\title{
Enhanced Sliding Mode Control for a Nonlinear Active Suspension Full Car Model
}

\author{
Erliana Samsuria 1, ${ }^{*}$, Yahaya M. Sam ${ }^{2}$, Fazilah Hassan ${ }^{3}$ \\ Control \& Mechatronic Engineering, School of Electrical Engineering, Faculty of Engineering, University Teknologi \\ Malaysia, UTM Skudai 81310 \\ 1 erlianasha22@gmail.com; ${ }^{2}$ yahaya@utm.my; 3 fazilah@utm.my \\ * Corresponding Author
}

\section{ARTICLE INFO}

\section{Article history}

Received 05 October 2021

Revised 17 November 2021

Accepted 10 December 2021

\section{Keywords}

Active suspension;

Sliding mode control:

Nonlinear system;

Vibration control

\section{ABSTRACT}

This paper delivers findings on optimal robust control studies of nonlinear full car models. A nonlinear active suspension full car model is used, which considers the dynamic of a hydraulic actuator. The investigation on the benefit of using Sliding Mode Control (SMC) structure for the effective trade-off between road handling. The design of SMC in the chassis/internal subsystem is enhanced by modifying a sliding surface based on Proportional-Integral-Derivatives (PID) with the utilization of particle swarm optimization (PSO) algorithm in obtaining the best optimum value of control parameters. The switching control is designed through the Lyapunov function, which includes the boundedness of uncertainties in sprung masses that can guarantee the stability of the control design. The responses of the proposed controller have improved the disturbance rejection up to $60 \%$ as compared to the conventional SMC controller design and shown the high robustness to resist the effect of varying the parameter with minimal output deviations. The study proved that the proposed SMC scheme offers an overall effective performance in full car active suspension control to perform a better ride comfort as well as the road handling ability while maintaining a restriction of suspension travel. An intensive computer simulation (MATLAB Simulink) has been carried out to evaluate the effectiveness of the proposed control algorithm under various road surface conditions.

This is an open-access article under the CC-BY-SA license.

\section{Introduction}

The suspension system provides control towards the vehicle itself for having good road handling and ride comfort in the case of facing external disturbances and road irregularities while driving. Nowadays, the most local automotive industry mostly implies conventional suspension system's design that usually has an issue with load carrying, passenger comfort, and road handling [1]. There are three main types of suspension that have been used/studied invehicle systems, passive, semi-active and active suspension. The current automobile suspension system implies passive components, also known as a conventional suspension system that provides a non-controllable spring and damping coefficients with a fixed parameter. However, the trade-off between ride comfort, handling quality, and load varying is difficult to achieve 
since the parameters are fixed. The difference for semi-active suspension systems is the coefficient of dampers can be controlled [2]. In contrast to passive and semi-active, an active suspension system is able to enhance energy externally by the use of a force actuator to provide a closed-loop response for the system rather than dissipating the energy by the use of springs in passive. Many researchers nowadays are interested in developed suspension with active control automobile systems. Previous works of automobile systems focusing on the linear model of active suspension are adopted to propose various control strategies for different components to be controlled [1][2][3][4][5][6][7]. The proposed controller in the mentioned references has greatly improved the suspension performance; however, the dynamical effect of the system's behavior is being ignored. In fact, it is well known that the actuator behaves far from ideal in real life. In this work, the hydraulic actuator for the active suspension system model is chosen where the real implementation with its dynamic could easily be controlled to track the desired force with adequate techniques as reported in [8],[9],[10],[11],[12], and [13].

Most of the suspension control studies previously mainly focused on the quarter car model and half car model of the vehicle. These models were chosen due to the simplicity of the development of the mathematical modeling to represent the original system in an approximate and simplified manner [14][15][16]. The major concern is how it behaves like a real system since the full system of the vehicle or full car model is neglected. Therefore, the full car model is adopted as vehicle modeling in this work because it acted more realistic with the real car suspension system. The adopted model behaves similar to the real car model since it included all four actuator forces that exhibit three rotations in which heave, roll, pitch motions which are essential for the analysis of system performances whenever having a disturbance due to the roughness of the road surfaces. Moreover, most of the linear vehicle models in previous studies completely ignored the dynamical effect of system behavior in a specific condition. However, it is well known that the system dedicated with actuator behaves as highly nonlinear characteristics due to non-negligible dynamic and nonlinear components. This motivates the work to propose a robust controller design for an active suspension on a non-linear suspension system with an actuator dynamic included. The pairing of the nonlinear suspension system under the subjection of external disturbances causes the system dynamics to be considerably more complex. Thus, the controller design for a nonlinear system in this research work intends to design a control approach with a good tracking performance that is robust and insensitive to the parameter uncertainties and external disturbance. Based on intensive analysis of literature review, the Sliding Mode (SMC) is recognized as a nonlinear robust control method that possesses the dynamics of the system with an invariance property to uncertainties and external disturbance rejection once the system dynamics are controlled in the sliding mode by an appropriate design of switching function.

For a complex, full-scale model, the controller is designed for each of a separated subsystem which is the chassis and the other four sub-suspension pairing with the hydraulic actuator (actuation modules). The standard sliding surfaces offer limited flexibility on the constant gains as the error variables that will lead to the lower tracking accuracy and disturbance rejection ability. Thus, the proposed SMC controller in the chassis is designed with PID sliding surfaces that are able to directly adjust the proportional, integral, and derivative coefficients until the satisfied sliding condition can be achieved. The PID control algorithm is employed due to its simple feasibility and independent tuning parameters as a constant coefficient that is added into the sliding surfaces to improve the ability to resist the impact of external disturbances so that the system can generate the desired tracking force which able to attenuate the effect of vertical body motions and perform the better transient responses of the dynamic performances and steady-state accuracy as compared to the standard one. As the major nonlinearities of the model system come from the dynamic of the hydraulic actuator, the simple, robust SMC controller is designed for each of the actuation modules where it is divided into the separate tracking performance of the actuator force and the spool displacement. The developed control structures are designed to tackle the nonlinearity properties and track the desired variables according to 
its requirement. In addition, a robust control strategy with appropriate intelligent parameters tuning using particle swarm optimization (PSO) algorithm is utilized to obtain the optimal control performances of the controller design that is able to effectively overcome the occurrence of uncertainties and varying parameters in the system.

\section{Methods}

\subsection{System Modelling}

The inclusion of both pitch and roll motions in the suspension model serves what is known as a full car model. The study of ride comfort and vehicle handling much more depends on the combined effects of bounce, pitch, and roll for the development of a controller aimed towards the improvement of the system. Yet, the full active suspension model with seven degrees of freedom (7 D.O.F) that is utilized in this work inclusive of 3 DOF of vehicle body motions which are heave, pitch, and roll motions, and other 4 DOF of vertical direction motions, which are the front-right wheel, front-left wheel, rear-right wheel, and rear-left wheel motions. For simplicity, the assumptions for the simplified full car model are considered as in the presented works $[2][17][18]$,

i. Both suspension spring stiffness and damper behave as linear.

ii. The tire is modeled by linear spring while having no damping effect (neglected), and the tire is always in contact with road surfaces.

iii. The vehicle is a rigid body and has no rotational motion in the body and tire.

The simplified model of full-vehicle suspension system with 7 D.O.F is represented in Fig. $1(a)$, as used in [19], [15], [20], [21], [22]. The system consists of a single sprung mass (vehicle body) denoted as $Z_{b}$, connected to four unsprung masses denoted as $Z_{u i}$, which refer to wheel assembly were connected to the wheel at each corner. Spring force and damping force are denoted as $F_{s i}$ and $F_{d i}$, respectively. Briefly, all the notations with $i=1,2,3,4$ correspond to front-right $(f r)$, front-left $(f l)$, rear-right $(r r)$, and rear-left $(r l)$, respectively. The sprung mass/chassis subsystem consists of 3 D.O.F motions, including heave $\left(Z_{b}\right)$, pitch $\left(\theta_{b}\right)$ and roll $\left(\varphi_{b}\right)$. The active force, $f_{s i}$ is exerted by a hydraulic actuator located in between sprung and unsprung masses. In addition, the road input denoted as $Z_{r}$ has been subjected to each corner of the wheel.

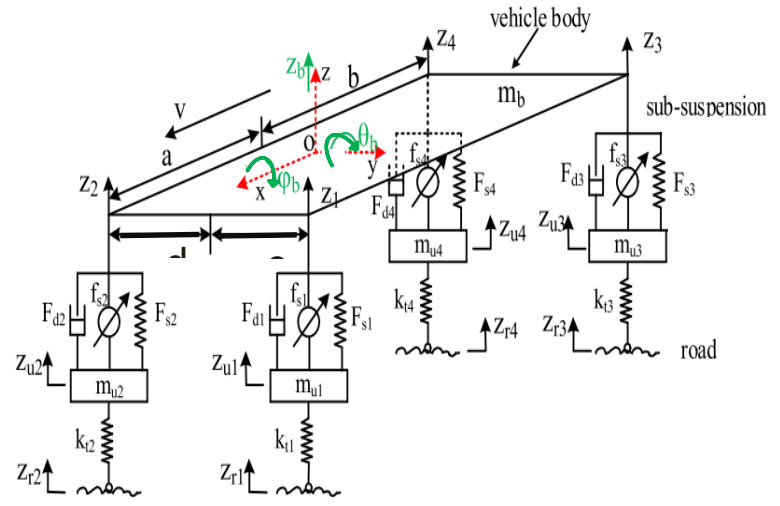

(a)

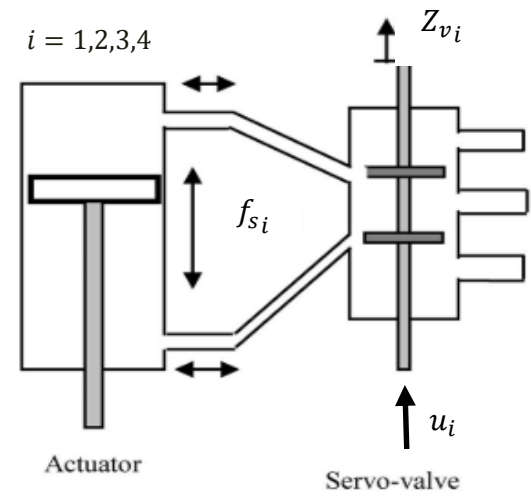

(b)

Fig. 1. Nonlinear active full car suspension system [22][23]

As the linear representation of system dynamics is insufficient and not always valid, a nonlinear model of the full car active suspension system adapted from [24][23] is utilized for the evaluation of the proposed controller design throughout this work. For the convenience of 
control, the model can be divided into two parts which are one on the internal chassis subsystem of 3 D.O.F motion of vehicle body and the other one is on the four sub-suspension systems that include the dynamic of hydraulic actuators, as depicted in Fig. 1(a).

The dynamic of 7 D.O.F of an active full car suspension can be derived by applying newton's second law of motion. Before that, let us define the suspension travel that is known as the expression as a function of the state components of physical relations within the chassis and its every four corners,

$$
\Delta Z_{i}=Z_{i}-Z_{u i} \quad ; \quad(i=1,2,3,4)
$$

where,

$$
\begin{aligned}
& Z_{1}=Z_{b}+a \sin \left(\theta_{b}\right)-c \sin \left(\varphi_{b}\right) \\
& Z_{2}=Z_{b}+a \sin \left(\theta_{b}\right)+d \sin \left(\varphi_{b}\right) \\
& Z_{3}=Z_{b}-b \sin \left(\theta_{b}\right)-c \sin \left(\varphi_{b}\right) \\
& Z_{4}=Z_{b}-b \sin \left(\theta_{b}\right)+d \sin \left(\varphi_{b}\right)
\end{aligned}
$$

where $a, b, c$, and $d$ are the distances of each suspension to the chassis subsystem.

The governing equations of motion for full car active suspension system after derivation from Newton's second law are obtained as follows,

Chassis (vehicle body) system:

$$
\begin{aligned}
m_{b} \ddot{Z}_{b}= & -k_{s_{1}}\left(Z_{1}-Z_{u_{1}}\right)-c_{s_{1}}\left(\dot{Z}_{1}-\dot{Z}_{\mathrm{u}_{1}}\right)-k_{\mathrm{s}_{2}}\left(Z_{2}-Z_{\mathrm{u}_{2}}\right)- \\
& -c_{\mathrm{s}_{2}}\left(\dot{Z}_{2}-\dot{Z}_{\mathrm{u}_{2}}\right)-k_{\mathrm{s}_{3}}\left(Z_{3}-Z_{u_{3}}\right)-c_{\mathrm{s}_{3}}\left(\dot{Z}_{3}-\dot{Z}_{\mathrm{u}_{3}}\right)-. . \\
& -k_{s_{4}}\left(Z_{4}-Z_{\mathrm{u}_{4}}\right)-c_{s_{4}}\left(\dot{Z}_{4}-\dot{Z}_{\mathrm{u}_{4}}\right)+F_{b} \\
\ddot{I}_{y} \ddot{\theta}_{b}= & a k_{s_{1}}\left(Z_{1}-Z_{u_{1}}\right)+a c_{s_{1}}\left(\dot{Z}_{1}-\dot{Z}_{\mathrm{u}_{1}}\right)+a k_{\mathrm{s}_{2}}\left(Z_{2}-Z_{\mathrm{u}_{2}}\right)+. . \\
& +a c_{\mathrm{s}_{2}}\left(\dot{Z}_{2}-\dot{Z}_{\mathrm{u}_{2}}\right)-b k_{\mathrm{s}_{3}}\left(Z_{3}-Z_{u_{3}}\right)-b c_{\mathrm{s}_{3}}\left(\dot{Z}_{3}-\dot{Z}_{\mathrm{u}_{3}}\right)-. . \\
- & b k_{s_{4}}\left(Z_{4}-Z_{\mathrm{u}_{4}}\right)-b c_{s_{4}}\left(\dot{Z}_{4}-\dot{Z}_{\mathrm{u}_{4}}\right)+F_{\theta b} \\
I_{x} \ddot{\varphi}_{b}= & d k_{s_{1}}\left(Z_{1}-Z_{u_{1}}\right)+d c_{s_{1}}\left(\dot{Z}_{1}-\dot{Z}_{\mathrm{u}_{1}}\right)-c k_{\mathrm{s}_{2}}\left(Z_{2}-Z_{\mathrm{u}_{2}}\right)-. . \\
& -c c_{\mathrm{s}_{2}}\left(\dot{Z}_{2}-\dot{Z}_{\mathrm{u}_{2}}\right)+d k_{\mathrm{s}_{3}}\left(Z_{3}-Z_{u_{3}}\right)+d c_{\mathrm{s}_{3}}\left(\dot{Z}_{3}-\dot{Z}_{\mathrm{u}_{3}}\right)-. . \\
& -c k_{s_{4}}\left(Z_{4}-Z_{\mathrm{u}_{4}}\right)-c c_{s_{4}}\left(\dot{Z}_{4}-\dot{Z}_{\mathrm{u}_{4}}\right)+F_{\varphi b}
\end{aligned}
$$

Four sub-suspension systems:

$$
\begin{aligned}
& m_{u_{1}} \ddot{Z}_{1}=k_{s_{1}}\left(Z_{1}-Z_{u_{1}}\right)+c_{s_{1}}\left(\dot{Z}_{1}-\dot{Z}_{\mathrm{u}_{1}}\right)-k_{\mathrm{t} 1}\left(Z_{\mathrm{u}_{1}}-Z_{r_{1}}\right)-f_{s_{1}} \\
& m_{u_{2}} \ddot{Z}_{2}=k_{\mathrm{s}_{2}}\left(Z_{2}-Z_{\mathrm{u}_{2}}\right)+c_{\mathrm{s}_{2}}\left(\dot{Z}_{2}-\dot{Z}_{\mathrm{u}_{2}}\right)-k_{\mathrm{t} 2}\left(Z_{\mathrm{u}_{2}}-Z_{r_{2}}\right)-f_{s_{2}} \\
& m_{u_{3}} \ddot{Z}_{3}=k_{\mathrm{s}_{3}}\left(Z_{3}-Z_{\mathrm{u}_{3}}\right)+c_{\mathrm{s}_{3}}\left(\dot{Z}_{3}-\dot{Z}_{\mathrm{u}_{3}}\right)-k_{\mathrm{t} 3}\left(Z_{\mathrm{u}_{3}}-Z_{r_{3}}\right)-f_{s_{3}} \\
& m_{u_{4}} \ddot{Z}_{4}=k_{s_{4}}\left(Z_{4}-Z_{\mathrm{u}_{4}}\right)+c_{s_{4}}\left(\dot{Z}_{4}-\dot{Z}_{\mathrm{u}_{4}}\right)-k_{\mathrm{t} 4}\left(Z_{\mathrm{u}_{4}}-Z_{r_{4}}\right)-f_{s_{4}}
\end{aligned}
$$

where $k_{s_{i}}$ and $c_{s_{i}}$ are stand for spring stiffness and damping coefficient, respectively for each of the corresponding suspension, $k_{\mathrm{t}_{i}}$ is a tire stiffness, $m_{b}$ and $m_{u_{i}}$ are denoted for sprung and 
unsprung masses, respectively, $I_{x}$ and $I_{y}$ are respectively roll and pitch moment of inertia of sprung mass. The relationship for actuation force exerted by, respectively, heave, pitch and roll motions satisfies that

$$
\begin{aligned}
& F_{b}=f_{s_{1}}+f_{s_{2}}+f_{s_{3}}+f_{s_{4}} \\
& F_{\theta b}=a\left(f_{s_{1}}+f_{s_{2}}\right)-b\left(f_{s_{3}}+f_{s_{4}}\right) \\
& F_{\varphi b}=d\left(f_{s_{1}}+f_{s_{3}}\right)-c\left(f_{s_{2}}+f_{s_{4}}\right)
\end{aligned}
$$

The dynamics of the hydraulic actuator, as referred to Fig. 1(b), are taken into account for a full-scale nonlinear model of a car suspension, by which the force is produced by the multiplication of the load pressure drops across the piston with the cross-sectional area of the piston itself, which in the mathematical equation the force is given by,

$$
f_{S_{i}}=\text { Area of piston }(A) \times \text { Load pressure }\left(P_{L}\right)
$$

Fig. 1(b) clearly showed the piston of the actuator is controlled by means of the voltage/current input to the electro-hydraulic servo valves in a three-lane four-way critical spool valve system [25][26]. The hydraulic actuator force is produced through the highpressure differences that occur in the piston due to the movement of a spool valve $\left(P_{L}\right)$ multiplied with the cross-sectional area $(A)$ of piston itself. The governing equations for the electro-hydraulic actuator can be structured into a simple form as modeled in [8][25][27][26], where the derivatives of the load pressure are given by

$$
\dot{P}_{L}=\alpha Q_{L}-\beta P_{L}-\alpha A\left(\dot{x}_{1}-\dot{x}_{2}\right)
$$

By upon substitution of $\alpha, \beta, \gamma$, which expressed as,

$$
\alpha=\frac{4 \beta_{e}}{V_{t}} \quad ; \quad \beta=\alpha C_{t m} \quad ; \quad \gamma=\alpha C_{d} w \sqrt{\frac{1}{\rho}}
$$

where $V_{t}$ is the total volume of the actuator, $\beta_{e}$ is the effective bulb modulus, $C_{t m}$ is the total leakage coefficient of a piston, $C_{d}$ is the discharge coefficient, $w$ is the spool valve area gradient, $x_{v}$ is the servo-valve displacement, and $\rho$ is the hydraulic fluid density. In the meantime, the resulting hydraulic flow rate, $Q L$ can be written as,

$$
Q_{L}=\gamma x_{v} \sqrt{P_{S}-\operatorname{sgn}\left(x_{v}\right) P_{L}}
$$

Then, assumed that servo valve that controls a motion of spool valve, $x_{v}$ as approximately a first-order linear system with a time constant, $\tau$ [9], as described in (5),

$$
\dot{x_{v}}=\frac{1}{\tau}\left(u-x_{v}\right)
$$

In addition, $x \in \mathfrak{R}^{22}$ is a state vector defined as in Table $\mathrm{A}$ in the Appendix.

\subsection{Proposed Method}

The design of active suspension control using the SMC approach is allocated for two fundamental parts in the system by which the chassis and the other four sub-suspension systems (actuation modules) as described in Fig. 2. The 3-DOF state variables in the chassis are first to be observed during a maneuver of the vehicle under the subjection of road input disturbances in order to minimize the undesired effect of heave, pitch, and roll motion on the passengers due to road irregularities. The proposed SMC is designed by defining a PID control algorithm as sliding surfaces on the dynamic of second-order chassis subsystem, and the enhanced control law of SMC is obtained based on the equivalent control law approach and the design of switching control through a Lyapunov stability function as to tackle the system's uncertainties. The second SMC design has two controllers that are formulated for each of the 
actuation modules, where it is divided into the separate tracking performance of the actuator force and the spool displacement. First, to provide the keen tracking of desired actuator forces by controlling the spool valve towards its desired position. Next, the needed spool valve position is further used to design four local control inputs from the hydraulic actuator to be fed to the system. Both controllers have employed first-order SMC control laws.

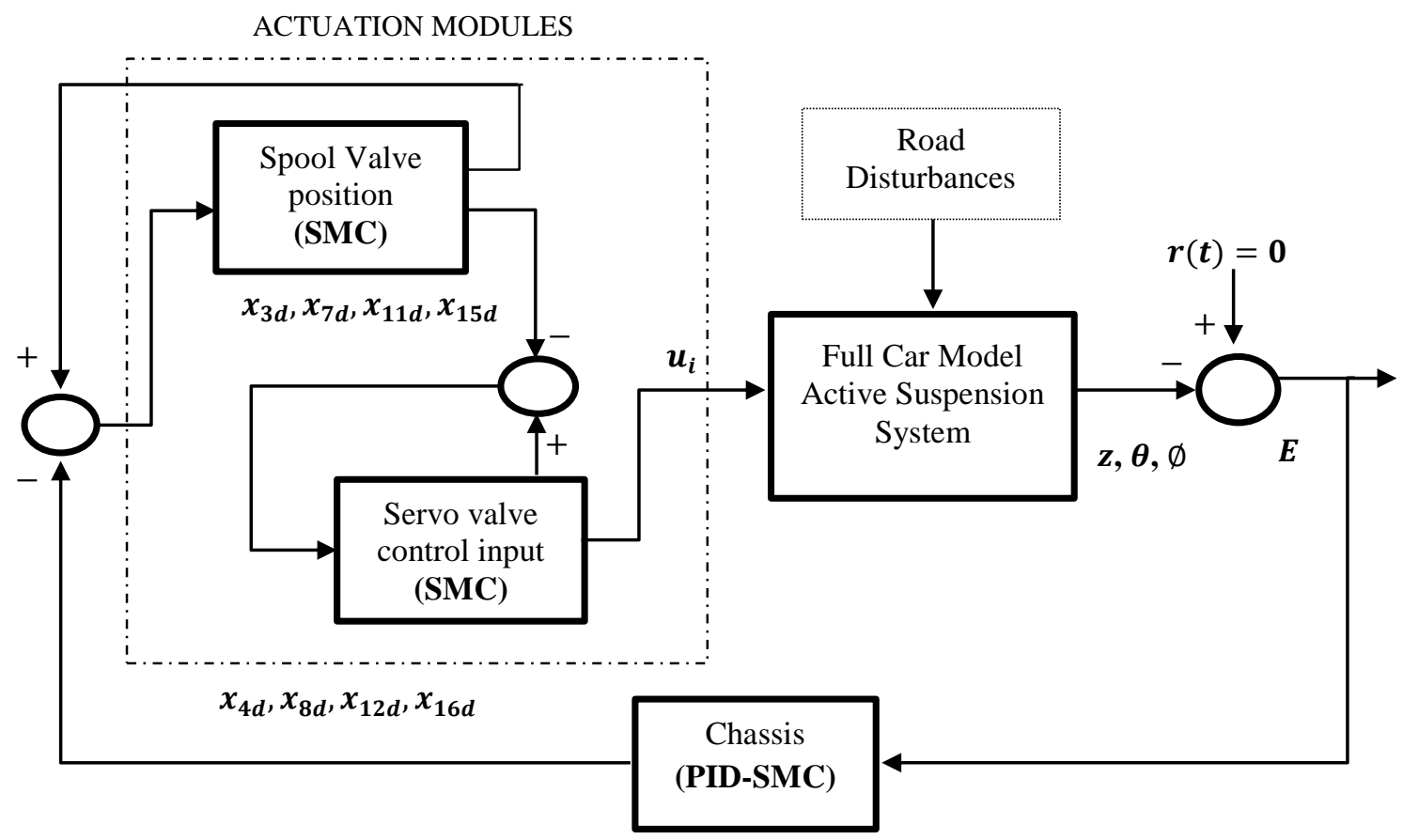

Fig. 2. The proposed method

\subsection{The Proposed PID-SMC Design in the Chassis Part}

The chassis subsystem can be described by following six equations obtained from mathematical modeling of the system, consider the separate function of the variables as follows, (notation $f r, f l, r r, r l$ used in the equations are stands for front-right, front-left, rear-right, and rear-left respectively),

$$
\dot{x}_{i}=f_{i}+g_{i} u_{i}
$$

With,

$$
\begin{aligned}
f_{18} & =\left\{k_{s_{f r}} x_{1}+k_{s_{f l}} x_{5}+k_{s_{r r}} x_{9}+k_{s_{r l}} x_{13}-\left(k_{s_{f r}}+k_{s_{f l}}+k_{s_{r r}}+k_{s_{r l}}\right) x_{17}-. .\right. \\
& -\left[a\left(k_{s_{f r}}+k_{s_{f l}}\right)-b\left(k_{s_{r r}}+k_{s_{r l}}\right)\right] \sin \left(x_{19}\right)-\left[d\left(k_{s_{f l}}+k_{s_{r l}}\right)-. .\right. \\
& \left.-c\left(k_{s_{f r}}+k_{s_{r r}}\right)\right] \sin \left(x_{21}\right)+c_{s_{f r}} x_{2}+c_{s_{f l}} x_{6}+c_{s_{r r}} x_{10}+c_{s_{r l}} x_{14}-. . \\
& -\left(c_{s_{f r}}+c_{s_{f l}}+c_{s_{r r}}+c_{s_{r l}}\right) x_{18}-\left[a\left(c_{s_{f r}}+c_{s_{f l}}\right)-b\left(c_{s_{r r}}+c_{s_{r l}}\right)\right] \times . . \\
& \left.\times \cos \left(x_{19}\right) x_{20}-\left[d\left(c_{s_{f l}}+c_{s_{r l}}\right)-c\left(c_{s_{f r}}+c_{s_{r r}}\right)\right] \cos \left(x_{21}\right) x_{22}\right\} / M \\
g_{18} & =\frac{1}{M} \\
f_{20} & =\cos \left(x_{19}\right) \times\left\{a k_{s_{f r}} x_{1}+a k_{s_{f l}} x_{5}-b k_{s_{r r}} x_{9}-b k_{s_{r l}} x_{13}-\left[a \left(k_{s_{f r}}+\ldots\right.\right.\right. \\
& \left.\left.+k_{s_{f l}}\right)-b\left(k_{s_{r r}}+k_{s_{r l}}\right)\right] x_{17}-\left[a^{2}\left(k_{s_{f r}}+k_{s_{f l}}\right)-b^{2}\left(k_{s_{r r}}+k_{s_{r l}}\right)\right] \times \ldots
\end{aligned}
$$




$$
\begin{aligned}
& \times \sin \left(x_{19}\right)-\left[d\left(a k_{s_{f l}}-b k_{s_{r l}}\right)-c\left(a k_{s_{f r}}-b k_{s_{r r}}\right)\right] \sin \left(x_{21}\right)+\cdots \\
& +a c_{s_{f r}} x_{2}+a c_{s_{f l}} x_{6}-b c_{s_{r r}} x_{10}-b c_{s_{r l}} x_{14}-\left[a\left(c_{s_{f r}}+c_{s_{f l}}\right)-\cdots\right. \\
& \left.-b\left(c_{s_{r r}}+c_{s_{r l}}\right)\right] x_{18}-\left[a^{2}\left(k_{s_{f r}}+k_{s_{f l}}\right)-b^{2}\left(k_{s_{r r}}+k_{s_{r l}}\right)\right] \cos \left(x_{19}\right) x_{20}-\cdots \\
- & {\left.\left[d\left(a c_{s_{f l}}-b c_{s_{r l}}\right)-c\left(a c_{s_{f r}}-b c_{s_{r r}}\right)\right] \cos \left(x_{21}\right) x_{22}\right\} / I_{y y} } \\
g_{20}= & \frac{1}{M} \\
f_{22}= & \cos \left(x_{21}\right) \times\left\{-c k_{s_{f r}} x_{1}+d k_{s_{f l}} x_{5}-c k_{s_{r r}} x_{9}+d k_{s_{r l}} x_{13}-\left[d \left(k_{s_{f l}}+\ldots\right.\right.\right. \\
+ & \left.\left.\left.k_{s_{r l}}\right)\right]-c\left(k_{s_{f r}}+k_{s_{r r}}\right)\right] x_{17}-\left[d\left(a k_{s_{f l}}-b k_{s_{r l}}\right)-c\left(a k_{s_{f r}}-b k_{s_{r r}}\right)\right] \times \ldots \\
\times & \sin \left(x_{19}\right)-\left[d^{2}\left(k_{s_{f l}}+k_{s_{r l}}\right)-c^{2}\left(k_{s_{f r}}+k_{s_{r r}}\right)\right] \sin \left(x_{21}\right)-\cdots \\
- & c c_{s_{f r}} x_{2}+d c_{s_{f l}} x_{6}-c c_{s_{r r}} x_{10}+d c_{s_{r l}} x_{14}-\left[d\left(c_{s_{f l}}+c_{s_{r l}}\right)-\ldots\right. \\
- & \left.c\left(c_{s_{f r}}+c_{s_{r r}}\right)\right] x_{18}-\left[d\left(a c_{s_{f l}}-b c_{s_{r l}}\right)-c\left(a c_{s_{f r}}-b c_{s_{r r}}\right)\right] \cos \left(x_{19}\right) x_{20} \\
- & {\left.\left[d^{2}\left(c_{s_{f l}}+c_{s_{r l}}\right)-c^{2}\left(c_{s_{f r}}+c_{s_{r r}}\right)\right] \cos \left(x_{21}\right) x_{22}\right\} / I_{x x} } \\
g_{22} & =\frac{1}{M}
\end{aligned}
$$

In order to ensure a preferable control effort for each heave $u_{z}$, pitch $u_{\theta}$, and roll $u_{\varphi}$ for a full car model, the controller is designed with defining the error between the actual and desired trajectory as follows,

$$
E=\left[\begin{array}{l}
e_{z} \\
e_{\theta} \\
e_{\varphi}
\end{array}\right]=\left[\begin{array}{l}
x_{17}-x_{17 d} \\
x_{19}-x_{19 d} \\
x_{21}-x_{21 d}
\end{array}\right]
$$

where the desired trajectory for a chassis part of the system is denoted as $x_{17 d}, x_{19 d}$, and $x_{21 d}$. The time derivatives of the error in (27) is

$$
\dot{E}=\left[\begin{array}{c}
\dot{e}_{z} \\
\dot{e}_{\theta} \\
\dot{e}_{\varphi}
\end{array}\right]=\left[\begin{array}{c}
\dot{x}_{17}-\dot{x}_{17 d} \\
\dot{x}_{19}-\dot{x}_{19 d} \\
\dot{x}_{21}-\dot{x}_{21 d}
\end{array}\right]=\left[\begin{array}{l}
x_{18}-x_{18 d} \\
x_{20}-x_{20 d} \\
x_{22}-x_{22 d}
\end{array}\right]
$$

The switching or sliding surface is designed by adopting PID control algorithm,

$$
u_{P I D}=k_{p} e+k_{i} \int e d t+k_{d} \frac{d e}{d t}
$$

where $k_{p}, k_{i}$ and $k_{d}$ are known as proportional, integral, and derivative control gains for the defined errors, respectively. These gains are positive constant of non-zero scalars will be further optimized using PSO algorithm.

Thus, PID sliding surfaces for heave, pitch, and roll are defined as

$$
S=\left[\begin{array}{c}
S_{z} \\
S_{\theta} \\
S_{\varphi}
\end{array}\right]=\left[\begin{array}{c}
k_{p z} e_{z}+k_{i z} \int e_{z} d t+k_{d z} \dot{e}_{z} \\
k_{p \theta} e_{\theta}+k_{i \theta} \int e_{\theta} d t+k_{d \theta} \dot{e}_{z} \\
k_{p \varphi} e_{\varphi}+k_{i \varphi} \int e_{\varphi} d t+k_{d \varphi} \dot{e}_{z}
\end{array}\right]
$$


The derivation of equation (30), along with the inclusive of system uncertainties in dynamic of the chassis model yields,

$$
\dot{S}=\left[\begin{array}{c}
\dot{S}_{z} \\
\dot{S}_{\theta} \\
\dot{S}_{\varphi}
\end{array}\right]=\left[\begin{array}{c}
k_{p z} \dot{e}_{z}+k_{i z} e_{z}+k_{d z}\left(f_{18}(x)+\Delta f_{18}(\mathrm{x})\right)+k_{d z}\left(g_{18}+\Delta g_{18}\right) u_{z}-k_{d z} \ddot{x}_{17 d} \\
k_{p \theta} \dot{e}_{\theta}+k_{i \theta} e_{\theta}+k_{d \theta}\left(f_{20}(x)+\Delta f_{20}(\mathrm{x})\right)+k_{d \theta}\left(g_{20}+\Delta g_{20}\right) u_{z}-k_{d \theta} \ddot{x}_{19 d} \\
k_{p \varphi} \dot{e}_{\varphi}+k_{i \varphi} e_{\varphi}+k_{d \varphi}\left(f_{22}(x)+\Delta f_{22}(\mathrm{x})\right)+k_{d \varphi}\left(g_{22}+\Delta g_{22}\right) u_{z}-k_{d \varphi} \ddot{x}_{21 d}
\end{array}\right]
$$

The equivalent control input for sliding mode is chosen to be linear, which means having no uncertainties by appointing a dynamic of sliding manifold $\dot{S}=0$ when $S=0$,

$$
u_{e q}=\left[\begin{array}{l}
u_{z e q} \\
u_{\theta e q} \\
u_{\varphi e q}
\end{array}\right]=\left[\begin{array}{c}
\left(k_{d z} g_{18}\right)^{-1}\left(k_{d z} \ddot{x}_{17 d}-k_{d z} f_{18}(x)-k_{p z} \dot{e}_{z}-k_{i z} e_{z}\right) \\
\left(k_{d \theta} g_{20}\right)^{-1}\left(k_{d \theta} \ddot{x}_{19 d}-k_{d \theta} f_{20}(x)-k_{p \theta} \dot{e}_{\theta}-k_{i \theta} e_{\theta}\right) \\
\left(k_{d \varphi} g_{22}\right)^{-1}\left(k_{d \varphi} \ddot{x}_{21 d}-k_{d \varphi} f_{22}(x)-k_{p \varphi} \dot{e}_{\varphi}-k_{i \varphi} e_{\varphi}\right)
\end{array}\right]
$$

by defining $\xi_{i}=k_{d_{i}} \ddot{x}_{\vartheta d}-k_{d_{i}} f_{18}(x)-k_{p_{i}} \dot{e}_{z}-k_{i_{i}} e_{z} ;\{i \in z, \theta, \varphi ; \vartheta=17,19,21\}$, thus eq. (32) becomes

$$
u_{e q}=\left[\begin{array}{l}
u_{z e q} \\
u_{\theta e q} \\
u_{\varphi e q}
\end{array}\right]=\left[\begin{array}{l}
\left(k_{d z} g_{18}\right)^{-1} \xi_{z} \\
\left(k_{d z} g_{20}\right)^{-1} \xi_{\theta} \\
\left(k_{d z} g_{22}\right)^{-1} \xi_{\varphi}
\end{array}\right]
$$

Next is designing the switching control input to obtain the total control input for SMC design. It should be designed properly to compensate for the system's uncertainties and thus stabilize the chassis system. To find the total control input of SMC that has two terms (equivalent and switching control inputs), defined as

$$
\left[\begin{array}{l}
u_{z} \\
u_{\theta} \\
u_{\varphi}
\end{array}\right]=\left[\begin{array}{l}
u_{z e q}+g_{18}{ }^{-1} u_{z s} \\
u_{\theta e q}+g_{20}{ }^{-1} u_{\theta s} \\
u_{\varphi e q}+g_{22}{ }^{-1} u_{\varphi s}
\end{array}\right]
$$

where $g_{18}, g_{20}$ and $g_{22}$ are the gains computed from (22), (24), (26), respectively.

Considers the Lyapunov stability function as

$$
V=\frac{1}{2} S_{z}^{2}+\frac{1}{2} S_{\theta}^{2}+\frac{1}{2} S_{\varphi}^{2}
$$

which has been defined based on all three chassis' sliding surfaces. Taking the first derivative of (34),

$$
\dot{V}=S_{z} \dot{S}_{z}+S_{\theta} \dot{S}_{\theta}+S_{\varphi} \dot{S}_{\varphi}
$$

By substituting Eq. (31-33) into (42) and recalled that $k_{d_{i}} \ddot{x}_{\vartheta d}-k_{d_{i}} f_{18}(x)-k_{p_{i}} \dot{e}_{z}-$ $k_{i_{i}} e_{z}=\xi_{i}$, where $\{i \in z, \theta, \varphi ; \vartheta=17,19,21\}$, the equation then yields,

$$
\begin{aligned}
\dot{V} & =S_{z}\left[k_{d z} \Delta f_{18}(x)+k_{d z} u_{z s}+\Delta g_{18}\left(g_{18}\right)^{-1} \xi_{z}+k_{d z} \Delta g_{18}\left(g_{18}\right)^{-1} u_{z s}\right]+. . \\
& +S_{\theta}\left[k_{d \theta} \Delta f_{20}(x)+k_{d \theta} u_{\theta s}+\Delta g_{20}\left(g_{20}\right)^{-1} \xi_{\theta}+k_{d \theta} \Delta g_{20}\left(g_{20}\right)^{-1} u_{\theta s}\right]+. . \\
& +S_{\varphi}\left[k_{d \varphi} \Delta f_{22}(x)+k_{d \varphi} u_{\varphi s}+\Delta g_{22}\left(g_{22}\right)^{-1} \xi_{\varphi}+k_{d \varphi} \Delta g_{22}\left(g_{22}\right)^{-1} u_{\varphi s}\right]
\end{aligned}
$$

Now, the assumption of the upper bounds of the uncertainties has been made to be known as in [23]. Hence, the relations of the boundedness are, 


$$
\begin{aligned}
& \left\|\Delta f_{18}(x)\right\| \leq \chi_{18} ; \quad\left\|\Delta f_{20}(x)\right\| \leq \chi_{20} ;\left\|\Delta f_{22}(x)\right\| \leq \chi_{22} \\
& \left\|\Delta g_{18}\left(g_{18}\right)^{-1}\right\| \leq B_{18}<1 ;\left\|\Delta g_{20}\left(g_{20}\right)^{-1}\right\| \leq B_{20}<1 ; \quad\left\|\Delta g_{22}\left(g_{22}\right)^{-1}\right\| \leq B_{22}<1
\end{aligned}
$$

where $\chi_{18}, \chi_{20}, \chi_{22}, b_{18}, B_{20}, b_{22}$ are design parameters with positive values which are set to satisfy the given inequalities. Thus, by implementing Eq. (37) into (36) yields

$$
\begin{aligned}
\dot{V}= & \left\|S_{z}\right\|\left(\chi_{18} k_{d z}+b_{18}\left|\xi_{z}\right|\right)+S_{z} k_{d z} u_{z s}+\left\|S_{z}\right\| 8_{18}\left\|u_{z s}\right\| k_{d z}+. . \\
& +\left\|S_{\theta}\right\|\left(\chi_{20} k_{d \theta}+b_{20}\left|\xi_{\theta}\right|\right)+S_{\theta} k_{d \theta} u_{\theta s}+\left\|S_{\theta}\right\| \beta_{20}\left\|u_{\theta s}\right\| k_{d \theta}+. . \\
& +\left\|S_{\varphi}\right\|\left(\chi_{22} k_{d \varphi}+B_{22}\left|\xi_{\varphi}\right|\right)+S_{\varphi} k_{d \varphi} u_{\varphi s}+\left\|S_{\varphi}\right\| 8_{22}\left\|u_{\varphi s}\right\| k_{d \varphi}
\end{aligned}
$$

Then, the switching control of SMC laws for heave, pitch, and roll $\left(u_{z s}, u_{\theta s}, u_{\varphi s}\right)$ is designed as follows,

$$
u_{z s}=-\frac{k_{z s}}{1+b_{18}} \frac{S_{z}}{\left\|S_{z}\right\|} \quad ; \quad u_{\theta s}=-\frac{k_{\theta s}}{1+b_{20}} \frac{S_{\theta}}{\left\|S_{\theta}\right\|} \quad ; \quad u_{\varphi s}=-\frac{k_{\varphi s}}{1+8_{22}} \frac{S_{\varphi}}{\left\|S_{\varphi}\right\|}
$$

where $k_{z s}=\frac{k_{z}}{k_{d z}}, k_{\theta s}=\frac{k_{\theta}}{k_{\theta z}}, k_{\varphi s}=\frac{k_{\varphi}}{k_{\varphi z}}$. Thus, substitute eq. (39) into (38), become,

$$
\begin{aligned}
\dot{V}= & \left\|S_{z}\right\|\left(\chi_{18} k_{d z}+B_{18}\left|\xi_{z}\right|-k_{z}\right)+\left\|S_{\theta}\right\|\left(\chi_{20} k_{d \theta}+B_{20} \xi_{\theta}-k_{\theta}\right)+. . \\
& +\left\|S_{\varphi}\right\|\left(\chi_{22} k_{d \varphi}+B_{22} \xi_{\varphi}-k_{\varphi}\right)
\end{aligned}
$$

If $k_{z}, k_{\theta}, k_{\varphi}$ are set as follows,

$$
k_{z}=\chi_{18} k_{d z}+\beta_{18}\left|Y_{z}\right| \quad ; \quad k_{\theta}=\chi_{20} k_{d \theta}+\beta_{20}\left|Y_{\theta}\right| \quad ; \quad k_{\varphi}=\chi_{22} k_{d \varphi}+\beta_{22}\left|Y_{\varphi}\right|
$$

Therefore, the eq. (40) results to

$$
\dot{V} \leq 0
$$

With this satisfying condition, the proposed SMC control design has guaranteed the stability of the chassis system. Nevertheless, the chattering phenomena that occur in the SMC phase may degrade the robustness of the controller. In order to reduce the chattering, the boundary thickness layer is introduced to approximate a discontinuous function in switching control law as follow,

$$
u_{z s}=-\frac{k_{z s}}{1+\beta_{18}} \frac{S_{z}}{\left\|S_{z}\right\|+\delta} \quad ; \quad u_{\theta s}=-\frac{k_{\theta s}}{1+\beta_{20}} \frac{S_{\theta}}{\left\|S_{\theta}\right\|+\delta} \quad ; \quad u_{\varphi s}=-\frac{k_{\varphi s}}{1+\beta_{22}} \frac{S_{\varphi}}{\left\|S_{\varphi}\right\|+\delta}
$$

where $\delta>0$ is a small positive scalar of the thickness boundary layer, which determines the quality of the approximation.

From the dynamic of the chassis model, it is clear that the relation between $u_{i}$ and the actuator pressure (state variables; $x_{3}, x_{7}, x_{11}, x_{15}$ ) is,

$$
\left[\begin{array}{l}
u_{z} \\
u_{\theta} \\
u_{\varphi}
\end{array}\right]=A_{p}\left[\begin{array}{cccc}
1 & 1 & 1 & 1 \\
a & a & -b & -b \\
-c & d & -c & d
\end{array}\right]\left[\begin{array}{l}
x_{3} \\
x_{7} \\
x_{11} \\
x_{15}
\end{array}\right], \quad\left[\begin{array}{l}
u_{z} \\
u_{\theta} \\
u_{\varphi}
\end{array}\right]=A_{p} M\left[\begin{array}{c}
x_{3} \\
x_{7} \\
x_{11} \\
x_{15}
\end{array}\right]
$$

where 


$$
\begin{aligned}
& M=\left[\begin{array}{cccc}
1 & 1 & 1 & 1 \\
a & a & -b & -b \\
-c & d & -c & d
\end{array}\right] \\
& {\left[\begin{array}{l}
x_{3} \\
x_{7} \\
x_{11} \\
x_{15}
\end{array}\right]=A_{p} M^{-1}\left[\begin{array}{l}
u_{z} \\
u_{\theta} \\
u_{\varphi}
\end{array}\right]}
\end{aligned}
$$

where $M^{+}=W^{+}\left(W W^{T}\right)^{-1}$ is the pseudo-inverse of matrix $N$. The values of $a, b, c, d$, and $A_{p}$ are defined in table 1 . The desired actuator pressures for the four subsystems are considered as the states in (45). Thus, we define $\left[\begin{array}{llll}x_{3 d} & x_{7 d} & x_{11 d} & x_{15 d}\end{array}\right]=\left[\begin{array}{llll}x_{3} & x_{7} & x_{11} & x_{15}\end{array}\right]$.

\subsection{The SMC Design for Actuation Modules}

\section{A. Actuator Force (Pressure) Tracking}

The SMC design for this part is to track the desired actuator force generated by the previous controller design (PID-SMC) in order to determine the needed position of the spool valve. Apart from this, this is predominantly insured by four local controllers for each subsystem $\{a \in(f r, f l, r r, r l)\}$. The desired actuator pressure is defined as

$$
\left[\begin{array}{llll}
x_{d p_{f r}} & x_{d p_{f l}} & x_{d p_{r r}} & x_{d p_{r l}}
\end{array}\right]=\left[\begin{array}{llll}
x_{3 d} & x_{7 d} & x_{11 d} & x_{15 d}
\end{array}\right]
$$

The pressure generated by the actuator is given by (which can clearly refer to system dynamic modeling equation),

$$
\dot{x}_{p_{a}}=-\beta x_{p_{a}}-\alpha A_{p}\left(\dot{z}_{s_{a}}-\dot{z}_{u_{a}}\right)+\operatorname{sign}\left(p_{s}-\operatorname{sign}\left(x_{v_{a}}\right) x_{p_{a}} \gamma \sqrt{\left|p_{s}-\operatorname{sign}\left(x_{v_{a}}\right) x_{p_{a}}\right|} x_{v_{a}}\right.
$$

with,

$$
f_{2_{a}}=-\beta x_{p_{a}}-\alpha A_{p}\left(\dot{z}_{s_{a}}-\dot{z}_{u_{a}}\right)
$$

And,

$$
g_{2_{a}}=\operatorname{sign}\left(p_{s}-\operatorname{sign}\left(x_{v_{a}}\right) x_{p_{a}} \gamma \sqrt{\left|p_{s}-\operatorname{sign}\left(x_{v_{a}}\right) x_{p_{a}}\right|} x_{v_{a}}\right.
$$

This notation is used in the place of state-space representation for the generalization of the second module in every four actuators. For the second and third modules, the SMC control law is designed based on the derivative of tracking error information, that is, the differences between actual and desired state variables.

In the meantime, defining the second sliding surface,

$$
S_{2_{a}}=x_{p_{a}}-x_{d p_{a}}
$$

It is taking a derivative of eq. (48) along with its derivation upon substitution of eq. (47), yields

$$
\dot{S}_{2_{a}}=f_{2_{a}}+g_{2_{a}} x_{v_{a}}-\dot{x}_{d p_{a}}
$$

Here the control input for the second SMC is defined as the state variables of the needed spool valve position $\left(x_{v_{a}}\right)$, thus the total control input of $x_{v_{a}}$ is selected as

$$
x_{v_{a}}=x_{u e v_{v_{a}}}+x_{u s_{v_{a}}}
$$

The equivalent control input of SMC is set by appointing a dynamic of sliding manifold $\dot{S}=0$,

$$
\begin{aligned}
& f_{2_{a}}+g_{2_{a}} x_{v_{a}}-\dot{x}_{d p_{a}}=0 \\
& x_{u e q_{v_{a}}}=g_{2_{a}}{ }^{-1}\left(\dot{x}_{d p_{a}}-f_{2_{a}}\right)
\end{aligned}
$$


The switching control is chosen as proportional rate reaching law which is defined to sufficiently satisfy the reachability condition $s \dot{s}<0$ or $s \dot{s} \leq-\eta|s|$ with $\eta>0$ [28].

$$
x_{u v_{v_{a}}}=-g_{2_{a}}{ }^{-1}\left(\omega_{2_{a}} S_{2_{a}}\right)
$$

Thus, the total SMC control input of $x_{v_{a}}$ results to,

$$
x_{v_{a}}=g_{2_{a}}{ }^{-1}\left(\dot{x}_{d p_{a}}-f_{2_{a}}-\omega_{2_{a}} S_{2_{a}}\right)
$$

Upon substitution of (55) into (61), the necessary spool valve position that will guarantee the actual output force by the actuator to approach the desired force can be given as,

$$
x_{v d_{a}}=\frac{\dot{x}_{p d_{a}}+\beta x_{p_{a}}+\alpha A_{p}\left(\dot{z}_{s_{a}}-\dot{z}_{u_{a}}\right)-\omega_{2_{a}} S_{2_{a}}}{\operatorname{sign}\left(p_{s}-\operatorname{sign}\left(x_{v_{a}}\right) x_{p_{a}} \gamma \sqrt{\left|p_{s}-\operatorname{sign}\left(x_{v_{a}}\right) x_{p_{a}}\right|}\right.}
$$

where $\omega_{2_{a}}$ is chosen to satisfy sliding convergences in finite time as mentioned, with $\{a \in(f r, f l, r r, r l)\}$, the notation of $\left(z_{s_{a}}-z_{u_{a}}\right)$ and $\left(\dot{z}_{s_{a}}-\dot{z}_{u_{a}}\right)$ are defined as suspension travel and its rate, respectively. It is the expression as a function of the state components of physical relations within the chassis $(z, \theta, \varphi)$ and its four corners. Taking a derivative of equations $(2-5)$ yields the respective rate of suspension travels as shown below,

$$
\begin{aligned}
& \dot{Z}_{1}=Z_{b}+a \dot{\theta}_{b} \cos \left(\theta_{b}\right)-c \dot{\varphi}_{b} \cos \left(\varphi_{b}\right) \\
& \dot{Z}_{2}=Z_{b}+a \dot{\theta}_{b} \cos \left(\theta_{b}\right)+d \dot{\varphi}_{b} \cos \left(\varphi_{b}\right) \\
& \dot{Z}_{3}=Z_{b}-b \dot{\theta}_{b} \cos \left(\theta_{b}\right)-c \dot{\varphi}_{b} \cos \left(\varphi_{b}\right) \\
& \dot{Z}_{4}=Z_{b}-b \dot{\theta}_{b} \cos \left(\theta_{b}\right)+d \dot{\varphi}_{b} \cos \left(\varphi_{b}\right)
\end{aligned}
$$

where $a, b, c$, and $d$ are the distances of each suspension to the chassis subsystem.

B. Spool Valve Displacement Tracking

The similar SMC design steps (in A) applied in this part to determine the required control input $u_{a}$ for servo valve by having a good tracking of the desired spool valve position in the previous SMC controller.

As known, the dynamic of spool valve dynamics in the system is given by,

$$
\dot{x}_{v_{a}}=\frac{1}{\tau}\left(u-x_{v_{a}}\right)
$$

Thus, the second sliding surface can be defined as,

$$
S_{3_{a}}=x_{v_{a}}-x_{d v_{a}}
$$

It is taking a derivative of (60) along with its derivation upon substitution of (59), yields

$$
\dot{S}_{3_{a}}=\frac{u-x_{v_{a}}}{\tau}-\dot{x}_{d v_{a}}
$$

The equivalent control input of the third SMC is set by appointing a dynamic of sliding manifold $\dot{S}=0$,

$$
u_{e q}=x_{v_{a}}-\tau \dot{x}_{d v_{a}}
$$

The third switching control also is chosen as proportional rate reaching law $\left(\omega_{3_{a}}\right)$ that is chosen to satisfy the reachability condition $\dot{s}<0$ or $\dot{s} \leq-\eta|s|$ in finite time,

$$
u_{s}=-\tau\left(\omega_{3_{a}} S_{3_{a}}\right)
$$


Briefly, the control input $u$ is expressed as follows,

$$
u=\left[\begin{array}{llll}
u_{d_{f r}} & u_{d_{f l}} & u_{d_{r r}} & u_{d_{r l}}
\end{array}\right]^{T}
$$

Thus. the total SMC control input of $u_{a}$ results to,

$$
\begin{aligned}
& u_{a}=x_{6}+\tau\left(\dot{x}_{v d_{a}}-\omega_{3_{a}} S_{3_{a}}\right) \\
& u_{a}=\left(1-\tau \omega_{3_{a}}\right) x_{v_{a}}+\tau \omega_{3_{a}} x_{v_{a}}+\tau \dot{x}_{v d_{a}}
\end{aligned}
$$

with defines the notation of $\{a \in(f r, f l, r r, r l)\}$.

\subsection{Optimization using PSO Algorithm}

There In obtaining the optimal controllable parameter used in the proposed SMC to assign into the system, the tuning method applied is based on the PSO algorithm, which was formerly introduced by James Kennedy and Russell C. Eberhart [29]. There are a lot of significant parameters that need to be set to ensure the searching process for the optimal point within the whole swarm. These particles include the number of particles that indicate the size of the swarm, the iteration numbers, the components of velocity, and the coefficient of acceleration.

In the searching process, each current particle will accelerate to the new searching point in every presence of a new position, depending on the velocity that will be set according to the previous velocity and best position. Each particle changes the searching point or position, $s_{i}$ with respect to its velocity, $v_{i}$ according to (67) and (68), respectively [30].

$$
\begin{aligned}
& v_{i}^{k+1}=w * v_{i}^{k}+c_{1} \operatorname{rand}_{i}\left(\text { pbest }_{i}-s_{i}^{k}\right)+c_{2} \operatorname{rand}_{i}\left(\text { gbest }_{i}-s_{i}^{k}\right) \\
& s_{i}^{k+1}=s_{i}^{k}+v_{i}^{k+1}
\end{aligned}
$$

where $i$ denotes as particle or agent values, $k$ represents the iteration of particle while $k+1$ as the future iteration of the particle, $c_{1}$ denotes the self-coefficient of acceleration for particle itself, $c_{2}$ denotes the swarm-coefficient of acceleration in the entire group, $w$ represents the inertia weighting value, pbest represents personal best value (particle's value), and gbest represents global best value (groups). The rand $_{i}$ represents as the random numbers that are to be assigned between $[0,1]$.

The momentum and competency of the particles in terms of exploration (finding a good optimum place through the different areas of swarm space) and exploitation (to search around the target point) so that they would not diverge from the search space are much influenced by the inertia weight. The best way is to set the inertia weight with a larger value at the beginning of the iteration to make the particles move freely in their exploration to every space in the swarm and decrease linearly with the iteration number to obtain a quick convergence and able to perform the exploitation. The inertia weight condition stated in [31] in order to satisfy these processes is given as,

$$
w^{t+1}=w_{\max }-\left(\frac{w_{\max }-w_{\min }}{t_{\max }}\right) * t
$$

Where $w_{\max }$ and $w_{\min }$ stand for the minimum and maximum values of the inertia weight, respectively, while the maximum number of iterations is denoted as $t_{\max }$ and the current number of iteration is denoted as $t$.

Fig. 3 illustrates the process step of the PSO algorithm to tune control parameters of the proposed controllers in obtaining an optimal value to guarantee the best performances of the controller. Here, the PSO algorithm proposed to search the best value of the control gains of PID in the sliding surfaces of the chassis and the control laws' gains of SMC in the actuation modules. 


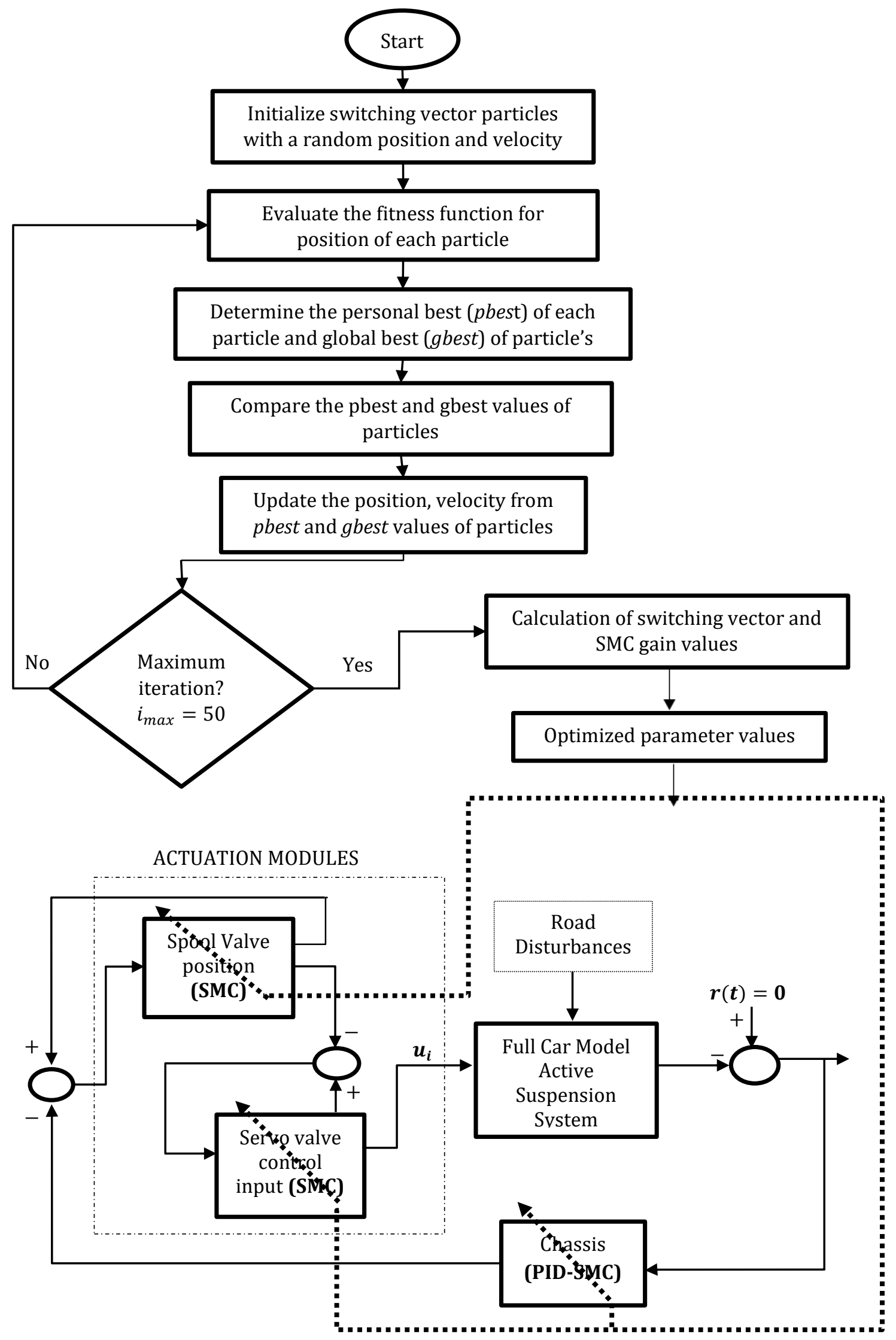

Fig. 3. Optimization using PSO Algorithm 


\section{Results and Discussion}

The simulation design of the nonlinear full car active suspension system with the adaptation of the proposed controller is carried out using MATLAB and Simulink based on the dynamic equations established in previous chapters. The obtaining results are significant in investigating the performances of the proposed PID-SMC-based active suspension along with the comparison with the benchmark controller and passive suspension.

In the simulation, a conventional Sliding Mode Controller (SMC) is utilized as the comparative method to evaluate the performances of the proposed controller for a nonlinear active suspension system. Indeed, the control values of the benchmark controller also have been tuned using the PSO algorithm so that the results to be compared are fair and appropriately conducted. Model parameters of nonlinear full car suspension system were adopted from [23] and [24], and the value of parameters used are tabulated in Table B as attached in the Appendix section. The related values of parameters of the proposed controller are tabulated as in Table 1. The values of boundedness constants from (49) are chosen based on the work reported in [23]. The boundary thickness layer is set to 0.8 as it is the preferable value to perform the best in obtaining the clear, smooth output results of the proposed controller.

Table 1. Control's parameter values

\begin{tabular}{ccc}
\hline Description & Parameter & Value \\
\hline \multirow{2}{*}{ System boundedness parameters } & $\chi_{18}, \chi_{20}, \chi_{22}$ & 2.4 \\
\cline { 2 - 3 } & $\beta_{18}, \beta_{20}, \beta_{22}$ & 0.2 \\
\hline Boundary thickness layer gain & $\delta$ & 0.8 \\
\hline Desired trajectory & $x_{17 d}, x_{19 d}, x_{21 d}$, & 0 \\
\hline
\end{tabular}

\subsection{Tuning Parameter based on PSO Algorithm}

The implementation of PSO fed to the algorithm in the proposed PID-SMC control has included the set values of their parameter as tabulated in Table 2. The number of particles should be assigned with considerable not too large nor too low as it will slow down the processing time when setting the large value of $N$. Otherwise, the particles might be trapped in the local minima as if $N$ is too low [32][33]. The values of acceleration coefficient for $c_{1}$ and $c_{2}$ are set to be similar as suggested in [34][35][36]. During the running process, the inertia weight will decrease linearly from within 0.9 to 0.4 , which are set as maximum and minimum values, respectively. The large value of inertia weight allows the particles to move freely in the search space. Then it will decrease over time to focus the searching activity in a smaller region [37]. The chosen maximum and minimum values of inertia weight are based on the other works reported from [34][38][31].

Table 2. PSO Control's parameter values

\begin{tabular}{lcc}
\hline \multicolumn{1}{c}{ Description } & Parameter & Value \\
\hline Number of particles & $N$ & 2.4 \\
\hline Maximum number of iterations & $t_{\max }$ & 50 \\
\hline Maximum Inertia weight & $w_{\text {imax }}$ & 0.9 \\
\hline Minimum Inertia weight & $w_{\text {imin }}$ & 0.4 \\
\hline Acceleration coefficient & $c_{1}, c_{2}$ & 2 \\
\hline Dimension of problems & & 5 \\
\hline
\end{tabular}

Integral Absolute Square Error (IASE) was utilized as an objective function that was used to calculate the minimum error produced in searching for the best values. The vertical body, pitch 
and heave acceleration, suspension travel, and wheel deflection were considered as the fitness function. It aims for minimizing the fitness function performance index as;

$$
\begin{aligned}
& J=J_{1}+J_{2}+J_{3}+J_{4}+J_{5} \\
& J=\int_{0}^{T}\left|\ddot{Z}_{b}\right|^{2} d t+\int_{0}^{T}\left|\ddot{\theta}_{b}\right|^{2} d t+\int_{0}^{T}\left|\ddot{\varphi}_{b}\right|^{2} d t+\int_{0}^{T} \sum_{i=f r, f l, r r, r l}\left|Z_{i}-Z_{u_{i}}\right|^{2} d t \\
& +\int_{0}^{T} \sum_{i=f r, f l, r r, r l}\left|Z_{u_{i}}-Z_{r_{i}}\right|^{2} d t
\end{aligned}
$$

where $T$ is the total time period.

The results from the tuning process in obtaining the optimal values of control parameters of the proposed PID-SMC-based active suspension are tabulated in Table 3.

Table 3. Optimal values of control parameters of the proposed PID-SMC method

\begin{tabular}{llccc}
\hline Controller & \multicolumn{1}{c}{ Description } & Parameter & Value \\
\hline & Proportional gain of respective heave, pitch, and roll & $k_{p z}, k_{p \theta}, k_{p \varphi}$, & 25 \\
\cline { 2 - 4 } PID-SMC & Integral gain of respective heave, pitch, and roll & $k_{i z}, k_{i \theta}, k_{i \varphi}$, & 13.9016 \\
\cline { 2 - 4 } & Derivative gain of respective heave, pitch, and roll & $k_{d z}, k_{d \theta}, k_{d \varphi}$, & 5.7771 \\
\cline { 2 - 5 } & Spool position SMC gain & $\omega_{2_{a}}$ & 17.4696 \\
\cline { 2 - 5 } & Control input SMC gain & $\omega_{3 a}$ & 10000 \\
\hline
\end{tabular}

*All the notations with $i=1,2,3,4$ correspond to front-right $(f r)$, front-left $(f l)$, rear-right ( $r r)$, and rearleft $(r l)$ respectively.

\subsection{Simulation Results}

For the assessment of the controller response, a double bump input bump input was implemented in this system as one of the types of road input profiles that acts as a road disturbance [5]. For the front right, the amplitude of the first and second bump was equally set to $0.11 \mathrm{~m}$ and $0.5 \mathrm{~m}$ respectively while front left is set to $0.08 \mathrm{~m}$ and $0.03 \mathrm{~m}$ respectively. Since it is assumed that the car is moving forward with a constant speed in which $v_{c}=22 \mathrm{~m} / \mathrm{s}$, the delay time can be computed for exerting the disturbances to the rear wheels. The time delay is $\tau_{c}=a+b / v_{c}$ where $a$ and $b$ are Distance from center of gravity to front and rear axle, that have set to $1.4 \mathrm{~m}$ and $1.7 \mathrm{~m}$, respectively. As a result, the rear right and rear left were designed as

$$
\begin{aligned}
z_{r r r} & =z_{r r r}(t-\tau) \\
z_{r r l} & =z_{r r l}(t-\tau)
\end{aligned}
$$

Some experimental simulation results are provided here to demonstrate the effectiveness of the proposed PID-SMC controller. In this section, the performances of the full-scale vehicle dynamic system are tested under the case of double bump input road profile, and the time domain of the responses is analyzed.

First, it is important to check is the controllability of the force tracking controller [26]. The force of tracking error of the hydraulic actuator model is measured using the proposed control algorithm for the particular road profile as a function of target force is shown in Fig. 4. It can be said that the output force generated by the hydraulic actuator has provided a good tracking effort with smooth variations according to the desired signal against a road perturbation.

Fig. 5 illustrates the variations of sliding surfaces and their corresponding control input signals for chassis state. From the figure, the sliding function is not zero $(s \neq 0)$ when facing the sudden changes in road profile but had settled down after a few seconds of reaction time. This means that the sliding mode arrives at the sliding manifold right after it had to go around in the 
reaching surface up to about $0.6 \mathrm{~s}$ to $1.5 \mathrm{~s}$ (according to each chassis state). The control input also showed zero fluctuations or signals once the sliding mode reached the sliding manifold. This manner has maintained the stability of the control system since it has satisfied the sliding condition to be converged and standstill in the manifold over a finite time.
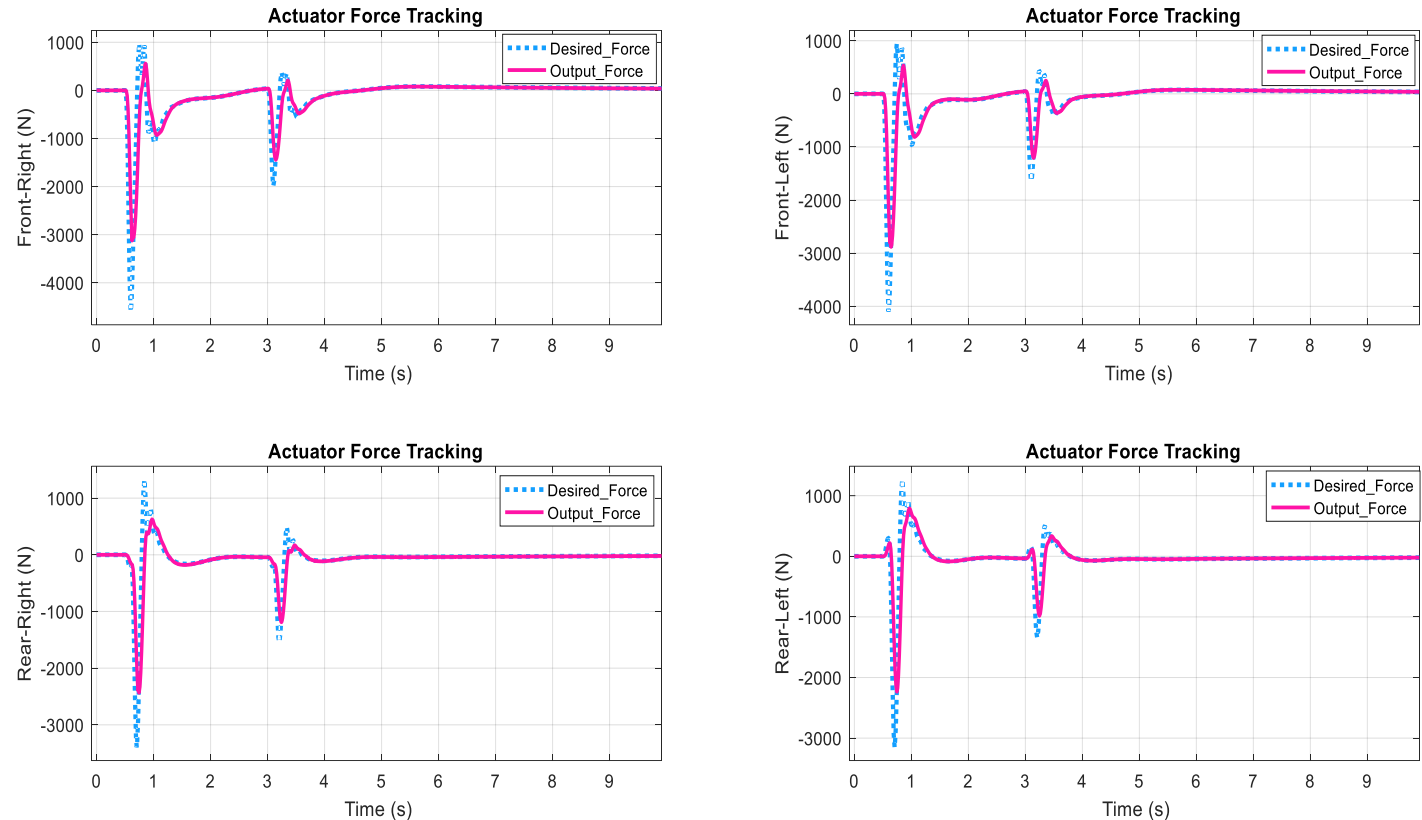

Fig. 4. Performances of force tracking for each of four actuators
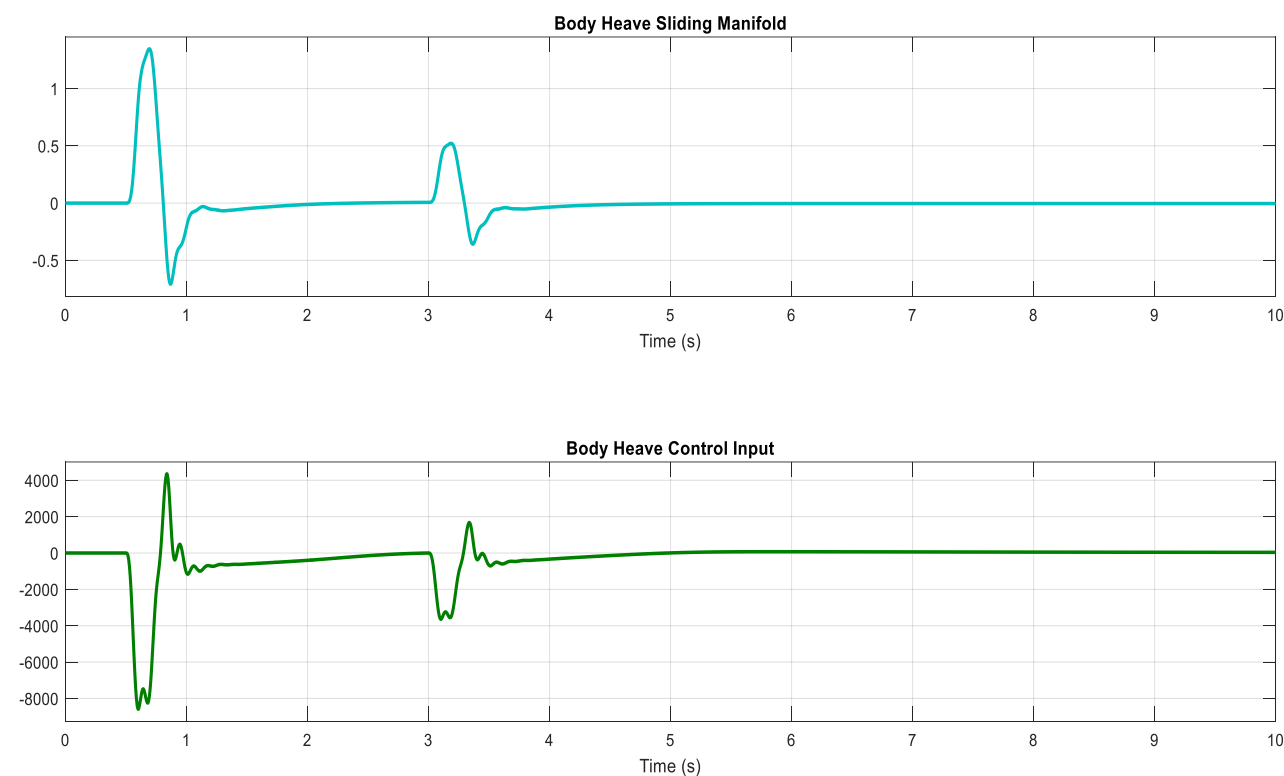

Fig. 5. Sliding surface and control input of body heave motion

The time response for an acceleration of the chassis states in terms of body-heave response, which is performance criteria related to riding comfort, also of pitch and roll response (vehicle handling) are given in Fig. 6. From the figures, it can be seen that the proposed PID-SMC controller outperformed the SMC controller that has attained a better transient behavior with a smaller amplitude and minimal oscillations. A sudden change of the road profile has produced a tremendous impact on the pitch and roll motions for active suspension control methods causes the improvement to be lower than in heave motions. However, a qualitative analysis of RMS values also proved that the proposed PID-SMC based active suspension control showed 
the superior performances improvement for heave, pitch, and roll accelerations with the reduction of the percentage of respective $33.16 \%, 52.39 \%$, and $48.94 \%$ over the SMC controller, and of respective $67.78 \%, 52.74 \%$ and $50.98 \%$ over the passive suspension system. These traits infer that the PID-SMC-based active suspension control possesses a good ride comfort and vehicle handling ability on the chassis under bump excitation.

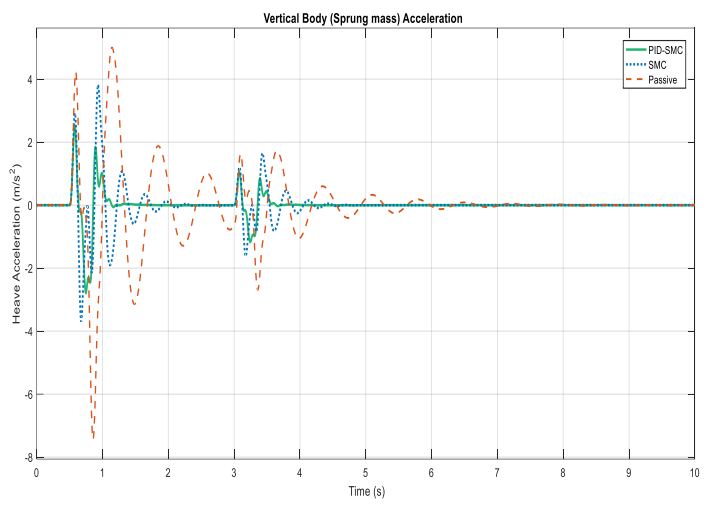

(a) Heave Acceleration

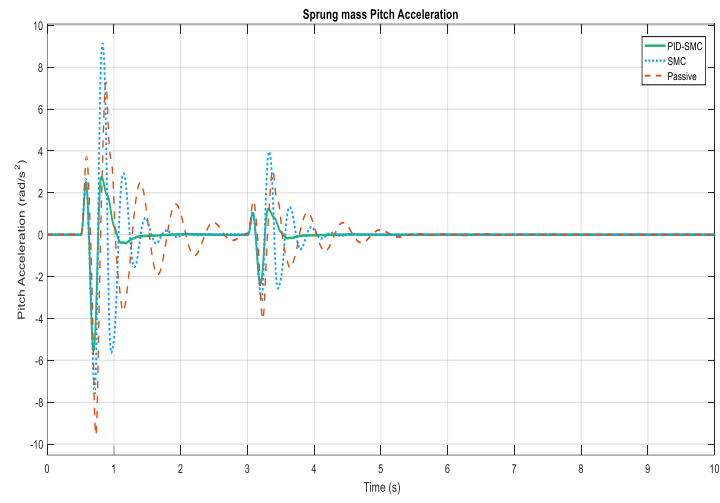

(b)Pitch Acceleration

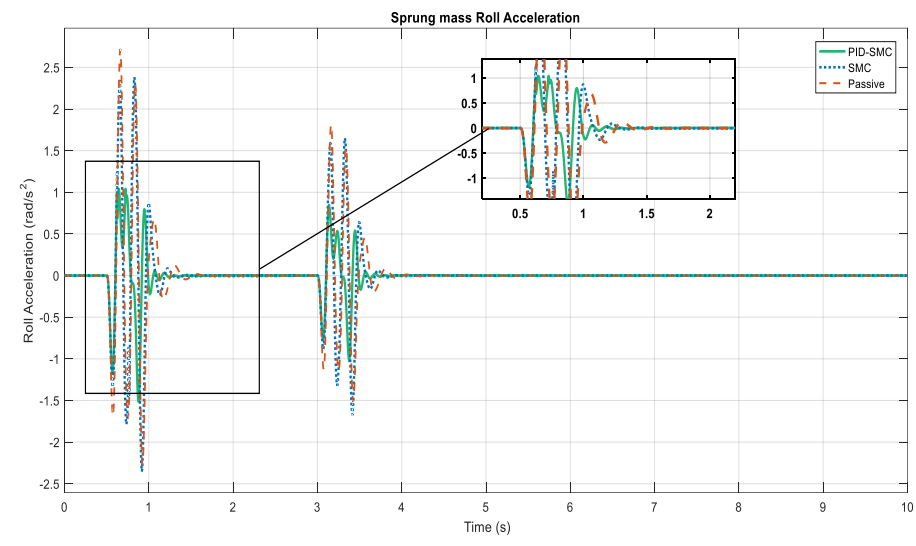

(c) Roll Acceleration

Fig. 6. Sprung mass acceleration responses

The responses of four suspension travel for active and passive suspension controls are illustrated in Fig. 7. The resulting signals for both PID-SMC-based and SMC active suspension controls have traveled within the permissible range limits $( \pm 10 \mathrm{~cm})$ in accordance with the performances specifications. Besides that, the figures also indicated they both had improved the rattle-space dynamic of the system with less noticeable vibrations/oscillations and faster settling time once the road bump had been passed. The responses of suspension travel for both PID-SMC-based and SMC active suspension controls in terms of RMS values are reduced significantly as compared to the passive one. These indicated that the proposed active suspension controls had the extent to improve the ride comfort performance of the system.

For road handling, considering the response of each of four tire deflections that determines how well the tires make contact with road surfaces as depicted in Fig. 8. The proposed method exhibits a smaller amplitude and is able to attenuate the vibration quickly after a short reaction time. Indeed, it can be told through the comparative analysis of the improvement percentages of tire deflections where the proposed method ensures an impressive reduction as much as $16.13 \%, 27.59 \%, 47.22 \%$, and $44.12 \%$ over the SMC-active suspension and $10.35 \%, 16 \%$, $52.5 \%$ and $51.28 \%$ over the passive suspension for a front-right, front-left, rear-right, and rear- 
left tires, respectively. It clearly implied that the PID-SMC-based method has a larger improvement upon the SMC-active suspension and passive, with a better grip of all four tires to the road surfaces when the vehicle is driven along the bumpy road. Hence, the major reduction in vibration of tire deflections for the proposed method had secured the system and ensured a preferable road handling ability of the active suspension system.
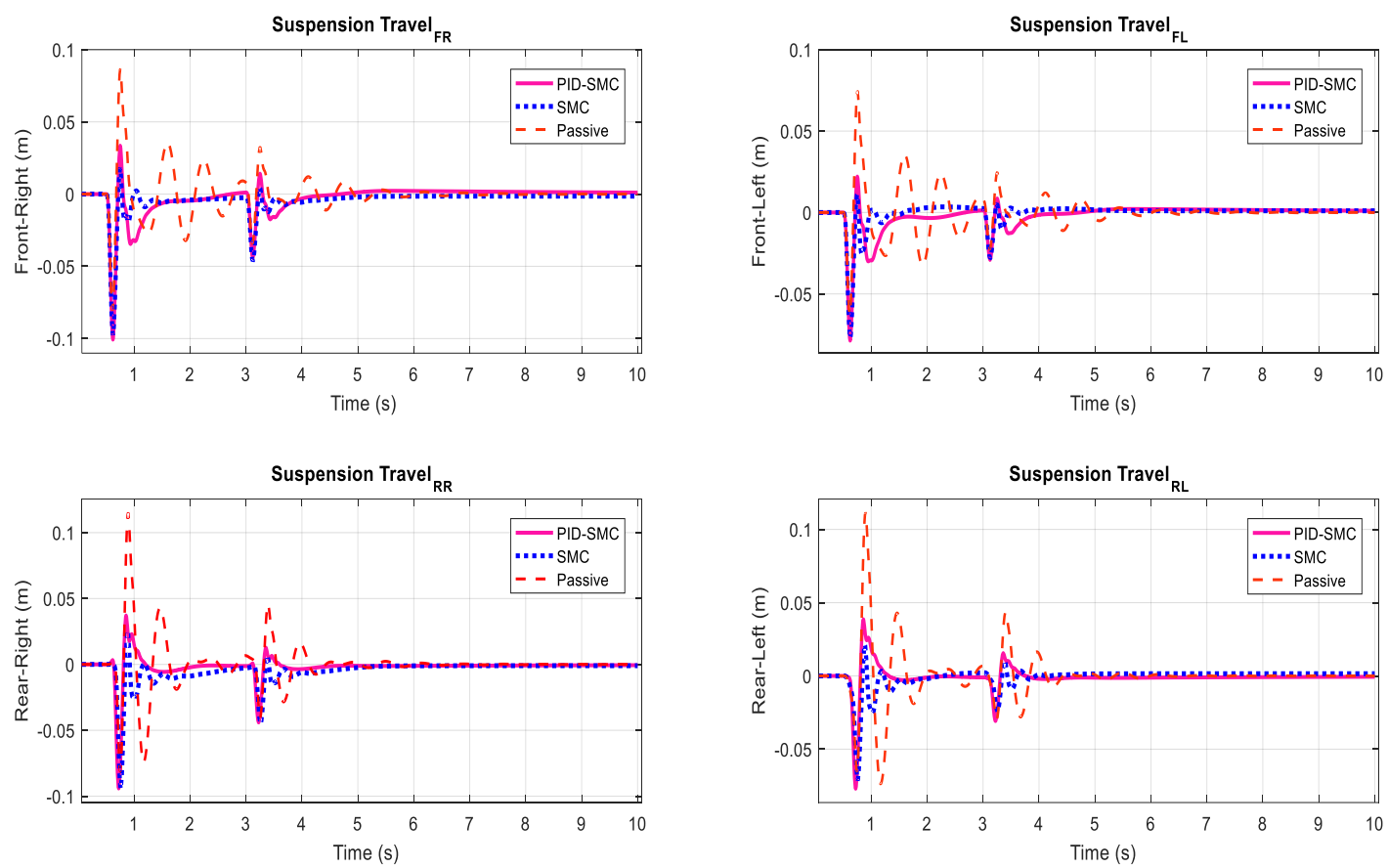

Fig. 7. Suspension travels between the body and each of the tire displacements
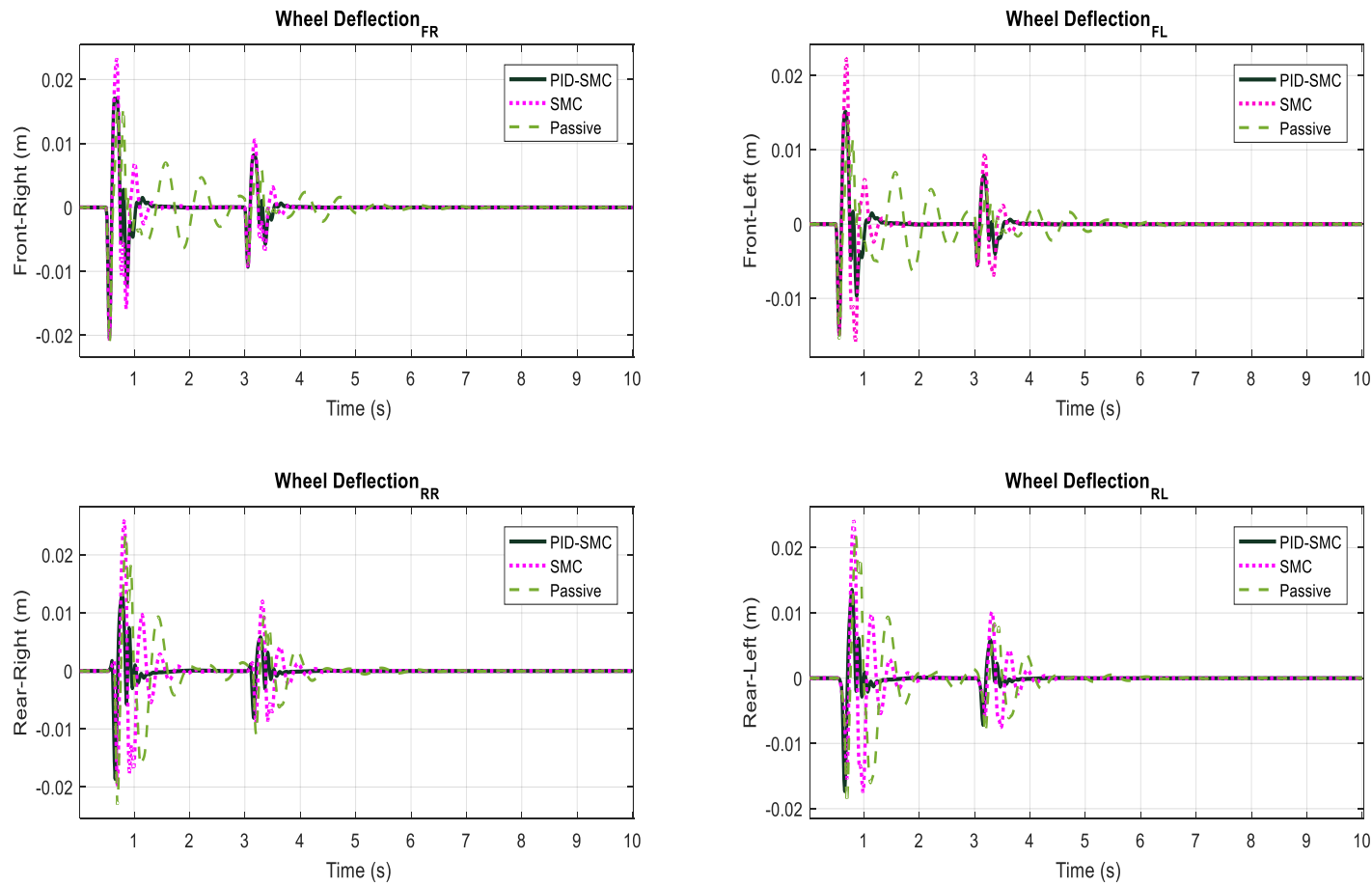

Fig. 8. Wheel deflections between body and each of tire displacements 


\section{Conclusion}

Good vertical control of the system can be achieved by having a robust control strategy that invariance to the perturbations of the road surfaces system uncertainties. Thus, this paper has presented the control strategies that combine the PID control with sliding mode control for the chassis subsystem in order to handle the perturbations by developing the needed tracking force to the actuation modules. Numerical and simulation results indicated that the performances of the acceleration of chassis states (heave, pitch, and roll motion), suspension travels, and wheel deflections for each of the tires in the case of the proposed controller outperformed the conventional SMC and passive suspension system. The combination of PID sliding surfaces and sliding mode control laws shows the controller exhibits good transient responses and higher percentages reduction in terms of RMS values as compared to the standard SMC laws. This attribute corresponds to the fast responses to alleviate the roll, pitch, and roll effects arising from the road irregularities. Moreover, they also demonstrated the effectiveness of the proposed SMC control structures had provided a stable impressive tracking control capability with smaller tracking errors that converge to zero, regardless of the input condition of the road disturbances. Hence, it has proved that the proposed method is splendidly robust and capable of achieving the trade-offs performances of ride comfort and road handling ability under the existences of uncertainties, parameter perturbations, and external road disturbances.

Author Contribution: All authors contributed equally to the main contributor to this paper. All authors read and approved the final paper.

Funding: This research received no external funding.

Conflicts of Interest: The authors declare no conflict of interest.

\section{Appendix}

Table A. State Vector of the dynamic system

\begin{tabular}{|c|c|c|c|}
\hline Subsystem & State Vector & Model Variable & Definition \\
\hline \multirow{16}{*}{$\begin{array}{l}\text { Four local } \\
\text { wheels }\end{array}$} & $x_{1}$ & $Z_{u_{1}}$ & Front-right unsprung mass displacement \\
\hline & $x_{2}$ & $\dot{Z}_{u_{1}}$ & Front-right unsprung mass velocity \\
\hline & $x_{3}$ & $A_{1}$ & Front-right actuator load pressure \\
\hline & $x_{4}$ & $Z_{v_{1}}$ & Front-right spool valve position \\
\hline & $x_{5}$ & $Z_{u_{2}}$ & Front-left unsprung mass displacement \\
\hline & $x_{6}$ & $\dot{Z}_{u_{2}}$ & Front-left unsprung mass velocity \\
\hline & $x_{7}$ & $A_{2}$ & Front-left actuator load pressure \\
\hline & $x_{8}$ & $Z_{v_{2}}$ & Front-left spool valve position \\
\hline & $x_{9}$ & $Z_{u_{3}}$ & Rear-right unsprung mass displacement \\
\hline & $x_{10}$ & $\dot{Z}_{u_{3}}$ & Rear-right unsprung mass velocity \\
\hline & $x_{11}$ & $A_{3}$ & Rear-right actuator load pressure \\
\hline & $x_{12}$ & $Z_{v_{3}}$ & Rear-right spool valve position \\
\hline & $x_{13}$ & $Z_{u_{4}}$ & Front-left unsprung mass displacement \\
\hline & $x_{14}$ & $\dot{Z}_{u_{4}}$ & Front-left unsprung mass velocity \\
\hline & $x_{15}$ & $A_{4}$ & Front-left actuator load pressure \\
\hline & $x_{16}$ & $Z_{v_{4}}$ & Front-left spool valve position \\
\hline \multirow{2}{*}{ Chassis } & $x_{17}$ & $Z_{b}$ & Heave displacement of the sprung mass \\
\hline & $x_{18}$ & $\dot{Z}_{b}$ & Heave velocity of the sprung mass \\
\hline
\end{tabular}




\begin{tabular}{cccl}
\hline Subsystem & State Vector & Model Variable & Definition \\
\hline$x_{19}$ & $\theta_{b}$ & Pitch angle of the sprung mass \\
\cline { 2 - 4 } & $\dot{\theta}_{20}$ & Pitch angular velocity of the sprung mass \\
\hline$x_{21}$ & $\varphi_{b}$ & The roll angle of the sprung mass \\
\hline$x_{22}$ & $\dot{\varphi}_{b}$ & Roll angular velocity of the sprung mass \\
\hline
\end{tabular}

Table B. Values of the Model Parameters

\begin{tabular}{ccc}
\hline Parameter & Symbol & Value \\
\hline Sprung mass & $m_{b}$ & $1500 \mathrm{~kg}$ \\
\hline Unsprung mass & $m_{u}$ & $59 \mathrm{~kg}$ \\
\hline Front spring stiffness & $k_{s 1}, k_{s 2}$ & $35000 \mathrm{Ns} / \mathrm{m}$ \\
\hline Rear spring stiffness & $k_{s 3}, k_{S 4}$ & $38000 \mathrm{Ns} / \mathrm{m}$ \\
\hline Wheels stiffness & $k_{t 1}, k_{t 2}, k_{t 3}, k_{t 4}$ & $190000 \mathrm{~N} / \mathrm{m}$ \\
\hline Front damping coefficient & $c_{s 1}, c_{s 2}$ & $1000 \mathrm{~N} / \mathrm{m}$ \\
\hline Rear damping coefficient & $c_{s 3}, c_{s 4}$ & $1100 \mathrm{~N} / \mathrm{m}$ \\
\hline Actuator Parameters & $\alpha, \beta, \gamma$ & $4.515 \times 10^{13} \mathrm{~N} / \mathrm{m}^{5}, 1$ \\
\hline Area of piston & $A_{p}$ & $1.545 \times 10^{9} \mathrm{~N} / \mathrm{m}^{5 / 2} / \mathrm{kg}^{1 / 2}$ \\
\hline Pressure supply to piston & $P_{s}$ & $1.35 \times 10^{-4} \mathrm{~m}^{2}$ \\
\hline Servo-valve time constant & $\tau$ & $10342500 \mathrm{~Pa}$ \\
\hline Centre of gravity to front axle distance & $a$ & $0.003 \mathrm{~s}$ \\
\hline Centre of gravity to front axle distance & $b$ & $1.4 \mathrm{~m}$ \\
\hline Centre of gravity to the right side & $c$ & $1.7 \mathrm{~m}$ \\
\hline Centre of gravity to the left side & $d$ & $1.5 \mathrm{~m}$ \\
\hline
\end{tabular}

${ }^{*}$ All the notations with $i=1,2,3,4$ corresponds to front-right (fr), front-left $(f l)$, rear-right ( $\left.r r\right)$ and rear-left $(r l)$, respectively.

\section{References}

[1] A. Agharkakli, G. S. Sabet, and A. Baraouz, "Simulation and Analysis of Passive and Active Suspension System Using Quarter Car Model for Different Road Profile," Int. J. Eng. Trends Technol., vol. 3, no. 5, pp. 636-644,

2012. https://citeseerx.ist.psu.edu/viewdoc/download?doi=10.1.1.1057.3389\&rep=rep1\&type=pdf

[2] C. Kuber, "Modelling Simulation and Control of an Active Suspension System," J. Impact Factor, Int. J. Mech. Eng. Technol., vol. 5, no. 11, pp. 66-75, 2014.

[3] E. Akbari and M. Farsadi, "Observer design for active suspension system using sliding mode control," in (SCOReD), 2010 IEEE, 2010, pp. 13-14. https://doi.org/10.1109/SCORED.2010.5704003

[4] S. Wen, M. Z. Q. Chen, Z. Zeng, X. Yu, and T. Huang, "Fuzzy Control for Uncertain Vehicle Active Suspension Systems via Dynamic Sliding-Mode Approach," IEEE Trans. Syst. Man, Cybern. Syst., vol. 47, no. 1, pp. 24-32, 2017. https://doi.org/10.1109/TSMC.2016.2564930

[5] Y. Md. Sam, J. H. S. Osman, and M. R. Abd. Ghani, "Sliding Mode Control of Active Suspension System," J. Teknol., vol. 37, no. 1, pp. 1-10, 2002. https://doi.org/10.11113/jt.v36.574

[6] M. F. Ismail, K. Peng, N. Hamzah, Y. M. Sam, M. K. Aripin, and M. H. Che Hasan, "A linear model of quarter car active suspension system using composite nonlinear feedback control," in 2012 IEEE Student Conference on Research and Development (SCOReD), 2012, pp. 98-103. https://doi.org/10.1109/SCOReD.2012.6518619 
[7] M. Das, "Designing Optimal Controller for Linear Multi-Input Multi- Output Uncertain Systems via Second Order Sliding Mode," Int. J. Electron. Electr. Comput. Syst., vol. 7, no. 3, pp. 290-298, 2018.

[8] A. Alleyne and J. K. Hedrick, "Nonlinear Adaptive Control of Active Suspensions," IEEE Trans. Control Syst. Technol., vol. 3, no. 1, pp. 94-101, 1995. https://doi.org/10.1109/87.370714

[9] A. Alleyne, P. D. Neuhaus, and J. K. Hedrick, "Vehicle System Dynamics : International Journal of Vehicle Mechanics and Mobility Application of Nonlinear Control Theory to Electronically Controlled Suspensions," Appl. Nonlinear Control Theory to Electron. Control. Suspens. Veh. Syst. Dyn. Int. J. Veh. Mech. Mobil., vol. 22, no. 5-6, pp. 309-320, 1993. https://doi.org/10.1080/00423119308969033

[10] P. Chen and A. Huang, "Vehicle System Dynamics : International Journal of Vehicle Mechanics and Adaptive sliding control of active suspension systems with uncertain hydraulic actuator dynamics," Veh. Syst. Dyn. Int. J. Veh. Mech. Mobil., vol. 44, no. 5, pp. 357-368, 2006. https://doi.org/10.1080/00423110600621664

[11] Y. M. Sam and K. Hudha, "Modelling and Force Tracking Control of Hydraulic Actuator for an Active Suspension System," in 2006 1ST IEEE Conference on Industrial Electronics and Applications, 2006, pp. 1-6. https://doi.org/10.1109/ICIEA.2006.257242

[12] H. Hashemipour and A. N. Model, "Nonlinear Optimal Control of Vehicle Active Suspension Considering Actuator Dynamics," Int. J. Mach. Learn. Comput., vol. 2, no. 4, pp. 355-359, 2012. https://doi.org/10.7763/IJMLC.2012.V2.144

[13] X. Li, Z.-C. Zhu, G.-C. Rui, D. Cheng, G. Shen, and Y. Tang, "Force Loading Tracking Control of an Electro-Hydraulic Actuator Based on a Nonlinear Adaptive Fuzzy Backstepping Control Scheme," Symmetry (Basel)., vol. 10, p. 155, 2018. https://doi.org/10.3390/sym10050155

[14] R. Guclu, "Active Control of Seat Vibrations of a Vehicle Model Using Various Suspension Alternatives," in Turkish J. Eng. Env. Sci., 2003, vol. 27, pp. 361-373. https://journals.tubitak.gov.tr/engineering/abstract.htm?id=6586

[15] A. B. Raju and R. Venkatachalam, "Analysis of Vibrations of Automobile Suspension System Using Full-car Model," Int. J. Sci. Eng. Res., vol. 4, no. 9, pp. 2105-2111, 2013. https://www.ijser.org/researchpaper/analysis-of-vibrations-of-automobile-suspension-systemusing-full-car-model.pdf

[16] V. Vidya, E. Engineering, and A. V. Vidyapeetham, "Model Reference Based Intelligent Control of an Active Suspension System for Vehicles," in International Conference on circuits Power and Computing Technologies [ICCPCT], 2017, pp. 1-5. https://doi.org/10.1109/ICCPCT.2017.8074362

[17] P. Sathishkumar, J. Jancirani, D. John, and S. Manikandan, "Mathematical modelling and simulation quarter car vehicle suspension,” IOSR J. Mech. Civ. Eng., vol. 3, no. 1, pp. 1280-1283, 2014. http://www.ijirset.com/upload/2014/icets/274_ME513.pdf

[18] A. G. Mohite and A. C. Mitra, "Development of Linear and Non-linear Vehicle Suspension Model," Mater. Today Proc., vol. 5, no. 2, pp. 4317-4326, 2018. https://doi.org/10.1016/j.matpr.2017.11.697

[19] A. Shirahatti, P. S. S. Prasad, P. Panzade, and M. M. Kulkarni, "Optimal design of passenger car suspension for ride and road holding," J. Brazilian Soc. Mech. Sci. Eng., vol. 30, no. 1, pp. 66-76, 2008. https://doi.org/10.1590/S1678-58782008000100010

[20] M. Hamed, B. Tesfa, F. Gu, and A. D. Ball, "A study of the suspension system for the diagnosis of dynamic characteristics," ICAC 2014 - Proc. 20th Int. Conf. Autom. Comput. Futur. Autom. Comput. Manuf., no. September, pp. 152-157, 2014. https://doi.org/10.1109/IConAC.2014.6935478

[21] J. Sun, J. Cong, L. Gu, and M. Dong, "Higher order sliding mode control for active suspension systems subject to actuator faults and disturbances," J. Multi-body Dyn., vol. 233, no. 2, pp. 280-298, 2018. https://doi.org/10.1177\%2F1464419318762887

[22] M. Du, D. Zhao, B. Yang, and L. Wang, "Terminal sliding mode control for full vehicle active suspension systems," J. Mech. Sci. Technol., vol. 32, no. 6, pp. 2851-2866, 2018. https://doi.org/10.1007/s12206-018-0541-x 
[23] M. Moradi and A. Fekih, "Adaptive PID-Sliding-Mode Fault-Tolerant Control Approach for Vehicle Suspension Systems Subject to Actuator Faults," IEEE Trans. Veh. Technol., vol. 63, no. 3, pp. 10411054, 2014. https://doi.org/10.1109/TVT.2013.2282956

[24] A. Chamseddine and H. Noura, "Control and Sensor Fault Tolerance of Vehicle Active Suspension," IEEE Trans. Control Syst. Technol., vol. 16, no. 3, pp. 416-433, 2008. https://doi.org/10.1109/TCST.2007.908191

[25] A. Dahunsi, "Neural Network-Based Model Predictive Control of a Servo-Hydraulic Vehicle Suspension System," in IEEE AFRICON, 2009, no. September, pp. 5-10. https://doi.org/10.1109/AFRCON.2009.5308111

[26] A. A. Shafie, "Active Vehicle Suspension Control using Electro Hydraulic Actuator on Rough Road Terrain," J. Adv. Res. Appl. Mech., vol. 9, no. No. 1, pp. 15-30, 2015. https://www.akademiabaru.com/doc/ARAMV9_N1_P15_30.pdf

[27] J. O. Pedro, M. Dangor, O. A. Dahunsi, and M. M. Ali, "Intelligent feedback linearization control of nonlinear electrohydraulic suspension systems using particle swarm optimization," Appl. Soft Comput. J., vol. 24, pp. 50-62, 2014. https://doi.org/10.1016/j.asoc.2014.05.013

[28] B. B. F. Deepak and K.-S. Kim, Sliding Mode Control Using Novel Sliding Surfaces. Springer, 2019.

[29] J. Kennedy and R. Eberhart, "Particle swarm optimization," Neural Networks, 1995. Proceedings., IEEE Int. Conf., vol. 4, pp. 1942-1948 vol.4, 1995. https://doi.org/10.1109/ICNN.1995.488968

[30] C. C. Soon, R. Ghazali, H. I. Jaafar, S. Y. S. Hussien, S. M. Rozali, and M. Z. A. Rashid, “Optimization of Sliding Mode Control using Particle Swarm Algorithm for an Electro-Hydraulic Actuator System," J. Telecommun. Electron. Comput. Eng., vol. 8, no. 7, pp. 71-76, 2016. https://core.ac.uk/download/pdf/235220835.pdf

[31] L. Ramli, Z. Mohamed, and H. I. Jaafar, "A neural network-based input shaping for swing suppression of an overhead crane under payload hoisting and mass variations," Mech. Syst. Signal Process., vol. 107, pp. 484-501, 2018. https://doi.org/10.1016/j.ymssp.2018.01.029

[32] A. M. Sharaf and A. A. A. El-Gammal, "A variable structure sliding mode particle swarm optimizationPSO optimal regulating controller for industrial pmdc motor drives," 2009 IEEE Int. Electr. Mach. Drives Conf. IEMDC '09, pp. 337-343, 2009. https://doi.org/10.1109/IEMDC.2009.5075227

[33] J. V. Ast, R. Babu, and B. D. Schutter, "Particle Swarms in Optimization and Control," in Proceedings of the 17th World Congress The International Federation of Automatic Control, vol. 41, no. 2, pp. 5131-5136, 2008. https://doi.org/10.3182/20080706-5-KR-1001.00862

[34] A. O. Bashir, X. Rui, L. K. Abbas, and J. Zhang, "Ride Comfort Enhancement of Semi-active Vehicle Suspension Based on SMC with PID Sliding Surface Parameters Tuning using PSO," Control Eng. Appl. Informatics, vol. 21, no. 3, pp. 51-62, 2019. https://doi.org/10.1109/ARTCom.2010.22

[35] K. Rajeswari and P. Lakshmi, "PSO optimized fuzzy logic controller for active suspension system," in Proceedings - 2nd International Conference on Advances in Recent Technologies in Communication and Computing, ARTCom 2010, 2010, pp. 278-283. https://doi.org/10.1016/j.ymssp.2018.08.022

[36] X. Ma, P. K. Wong, and J. Zhao, "Practical multi-objective control for automotive semi-active suspension system with nonlinear hydraulic adjustable damper," Mech. Syst. Signal Process., vol. 117, pp. 667-688, 2019. https://doi.org/10.1016/j.ymssp.2018.08.022

[37] E. Rakhshani, A. M. Cantarellas, D. Remon, A. Luna, and P. Rodriguez, "PSO-based LQR controller for multi modular converters," in 2013 IEEE ECCE Asia Downunder - 5th IEEE Annual International Energy Conversion Congress and Exhibition, IEEE ECCE Asia 2013, 2013, pp. 1023-1027. https://doi.org/10.1109/ECCE-Asia.2013.6579233

[38] C. C. Soon, R. Ghazali, C. S. Horng, C. M. Shern, and Y. Sam, "Controllers Capabilities with Computational Tuning Algorithm in Nonlinear Electro-Hydraulic Actuator System," J. Adv. Res. Fluid Mech. Therm. Sci., vol. 52, no. 2, pp. 148-160, 2018. https://www.akademiabaru.com/submit/index.php/arfmts/article/view/2386 